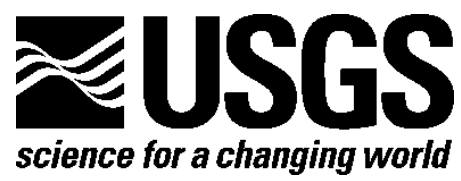

\title{
An Analysis of Three New Infrasound Arrays Around Kïlauea Volcano
}

By Weston A. Thelen and Jennifer Cooper

Open-File Report 2014-1253

U.S. Department of the Interior

U.S. Geological Survey 


\title{
U.S. Department of the Interior \\ SALLY JEWELL, Secretary
}

U.S. Geological Survey

Suzette M. Kimball, Acting Director

\author{
U.S. Geological Survey, Reston, Virginia: 2015
}

For more information on the USGS - the Federal source for science about the Earth, its natural and living resources, natural hazards, and the environment-visit http://www.usgs.gov or call 1-888-ASK-USGS

For an overview of USGS information products, including maps, imagery, and publications, visit $h$ ttp://www.usgs.gov/pubprod

To order this and other USGS information products, visit http://store.usgs.gov

Suggested citation:

Thelen, W.A., and Cooper, Jennifer, 2015, An analysis of three new infrasound arrays around Kīlauea Volcano: U.S. Geological Survey Open-File Report 2014-1253, 29 p., http://dx.doi.org/10.3133/ofr20141253.

Any use of trade, firm, or product names is for descriptive purposes only and does not imply endorsement by the U.S. Government.

Although this information product, for the most part, is in the public domain, it also may contain copyrighted materials as noted in the text. Permission to reproduce copyrighted items must be secured from the copyright owner.

ISSN 2331-1258 (online) 


\section{Contents}

Abstract

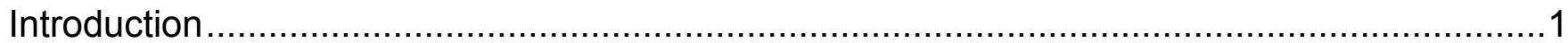

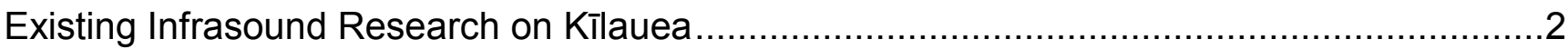

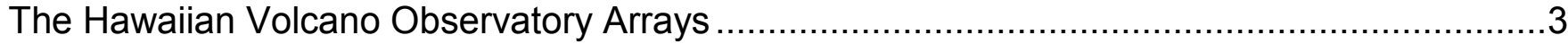

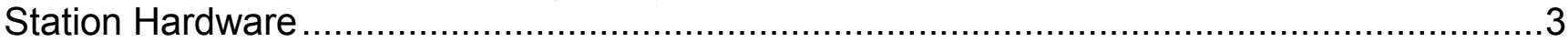

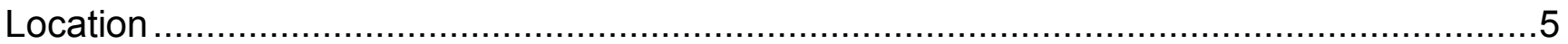

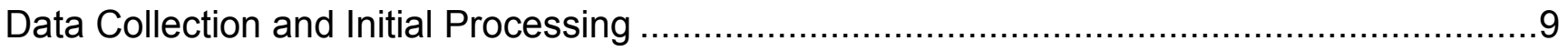

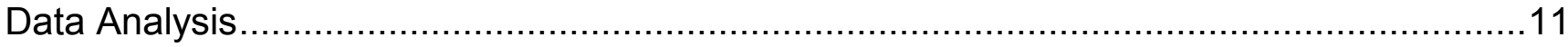

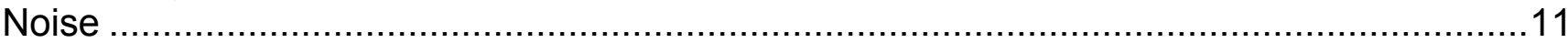

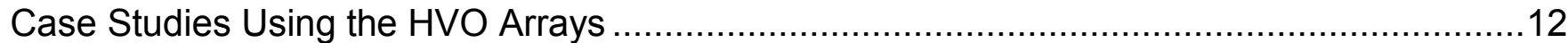

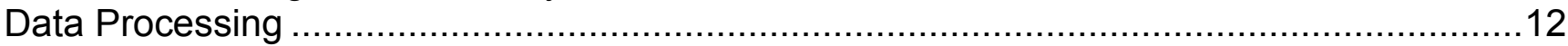

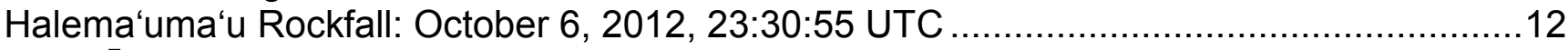

Pu'u ‘Ō'ō Pit Collapse: August 30, 2012, 20:05 UTC................................................... 19

Rise-Fall Cycle at Halema'uma'u Crater: October 19, 2012, 8:00-16:00 UTC .....................23

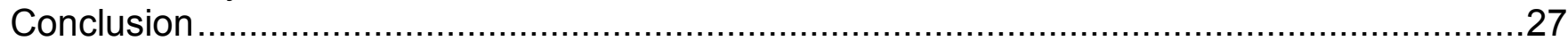

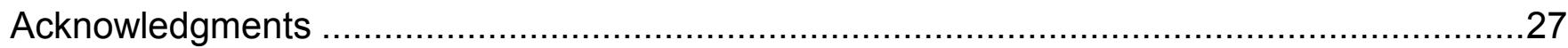

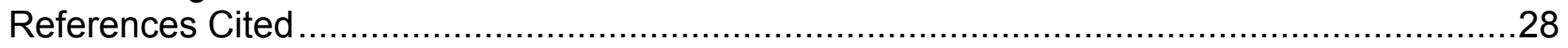

Figures

1. Photograph showing the pressure sensor instrumentation at each station. .................... 3

2. Photograph showing the pressure sensor enclosed in piping and resting on top of the bucket containing washed gravel and a buried screened inlet..................................... 4

3. Photograph showing the sensor and bucket at array AIND covered with a fake rock and placed in an ideal location in the shrubbery to reduce wind noise. .............................. 4

4. Map showing the arrays operated by the Hawaiian Volcano Observatory (HVO) located on the southern part of the Island of Hawai'i i.......................................................... 5

5. Plot showing the infrasound elements in the AHUD array. ......................................

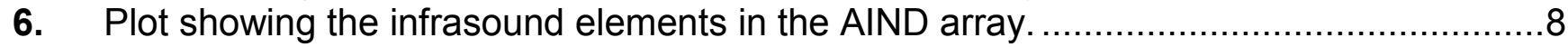

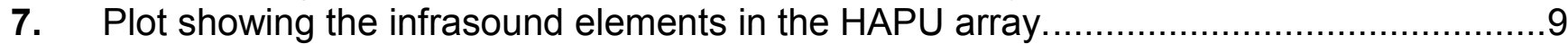

8. Flow chart detailing the path that infrasound data take before being stored.................10

9. Photographs showing the rockfall event at Halema'uma'u Crater on October 6, 2012. .12

10. Graph showing infrasound waveforms from the Halema'uma'u rockfall filtered above the microbarom........................................................................................... 14

11. Polar plots showing $f-k$ analysis of the Halema'uma'u rockfall at three infrasound arrays.......................................................................................................... 15

12. Graphs showing PMCC analysis of the Halema'uma'u rockfall at the AHUD array.......16

13. Graphs showing PMCC analysis of the Halema'uma'u rockfall at the AIND array.........17

14. Graphs showing PMCC analysis of the Halema'uma'u rockfall at the HAPU array. ......18

15. Histograms of the azimuth of signal detections for the PMCC analysis of the Halema'uma'u rockfall at three infrasound arrays. (1) (1) 4

(1)

8

8


21. Graphs showing the infrasound signal during the Halema'uma'u rise-fall cycle at AHUD array, element 04.

22. Graphs showing PMCC analysis of the Halema'uma'u rise-fall cycles at the AHUD

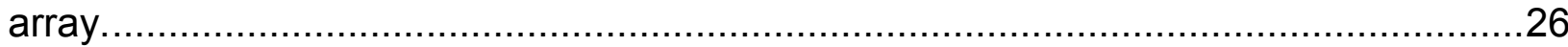

23. Rose plots showing PMCC analysis of the Halema'uma'u rise-fall cycle at the AHUD array

\section{Tables}

1. Critical sensor parameters for removing the instrument response of the infrasound sensors operated by the Hawaiian Volcano Observatory (HVO) on the Island of Hawai'i. .

2. Precise locations of infrasound stations and time of deployment on the Island of Hawai'i.

3. Infrasound arrays with the expected back azimuth, distance, and travel time to important sources across the Island of Hawai $i$. 


\section{Conversion Factors}

International System of Units to Inch/Pound

\begin{tabular}{llll}
\hline & Multiply & By obtain \\
\hline centimeter $(\mathrm{cm})$ & Length & \\
millimeter $(\mathrm{mm})$ & 0.3937 & inch (in.) \\
meter $(\mathrm{m})$ & 0.03937 & inch (in.) & foot (ft) \\
kilometer $(\mathrm{km})$ & 3.281 & mile (mi) \\
kilometer $(\mathrm{km})$ & 0.6214 & mile, nautical $(\mathrm{nmi})$ \\
meter $(\mathrm{m})$ & 0.5400 & yard (yd) \\
\hline & 1.094 & \\
\hline kilopascal $(\mathrm{kPa})$ & Pressure & \\
kilopascal $(\mathrm{kPa})$ & 0.009869 & atmosphere, standard $(\mathrm{atm})$ \\
kilopascal $(\mathrm{kPa})$ & 0.01 & bar \\
kilopascal $(\mathrm{kPa})$ & 0.2961 & inch of mercury at $60^{\circ} \mathrm{F}(\mathrm{in} \mathrm{Hg})$ \\
kilopascal $(\mathrm{kPa})$ & 0.1450 & pound-force per inch $(\mathrm{lbf} / \mathrm{in})$ \\
kilopascal $(\mathrm{kPa})$ & 20.88 & pound per square foot $\left(\mathrm{lb} / \mathrm{ft}^{2}\right)$ \\
\hline
\end{tabular}

Temperature in degrees Celsius $\left({ }^{\circ} \mathrm{C}\right)$ may be converted to degrees Fahrenheit $\left({ }^{\circ} \mathrm{F}\right)$ as ${ }^{\circ} \mathrm{F}=\left(1.8 \times{ }^{\circ} \mathrm{C}\right)+32$.

Temperature in degrees Fahrenheit $\left({ }^{\circ} \mathrm{F}\right)$ may be converted to degrees Celsius $\left({ }^{\circ} \mathrm{C}\right)$ as ${ }^{\circ} \mathrm{C}=\left({ }^{\circ} \mathrm{F}-32\right) / 1.8$.

\section{Datum}

Vertical coordinate information is referenced to the North American Vertical Datum of 1988 (NAVD 88).

Horizontal coordinate information is referenced to the North American Datum of 1983 (NAD 83).

Altitude, as used in this report, refers to distance above the vertical datum. 


\title{
An Analysis of Three New Infrasound Arrays Around Kïlauea Volcano
}

\author{
By Weston A. Thelen and Jennifer Cooper
}

\section{Abstract}

A network of three new infrasound station arrays was installed around Kîlauea Volcano between July 2012 and September 2012, and a preliminary analysis of open-vent monitoring has been completed by Hawaiian Volcano Observatory (HVO). Infrasound is an emerging monitoring method in volcanology that detects perturbations in atmospheric pressure at frequencies below $20 \mathrm{~Hz}$, which can result from volcanic events that are not always observed optically or thermally. Each array has the capability to detect various infrasound events as small as $0.05 \mathrm{~Pa}$ as measured at the array site. The infrasound monitoring network capabilities are demonstrated through case studies of rockfalls, pit collapses, and rise-fall cycles at Halema'uma'u Crater and $\mathrm{Pu}^{6} \mathrm{u}$ ' $\mathrm{O}^{`} \bar{o}$.

\section{Introduction}

Sound propagates through materials in a range of frequencies as a result of pressure changes within a medium. The human threshold for sound propagating through the atmosphere encompasses frequencies from $20 \mathrm{~Hz}$ to $20 \mathrm{kHz}$, and sound waves traveling through the atmosphere below $20 \mathrm{~Hz}$ are known as infrasound. These low-frequency waves can originate from a variety of sources including earth processes and anthropologic activities such as nuclear explosions, supersonic aircraft, aurora, and earthquakes (Bedard, 1971; Hedlin and others, 2002). Like audible sound, infrasound typically travels at $\sim 340 \mathrm{~m} / \mathrm{s}$ at $15^{\circ} \mathrm{C}$. Infrasound can vary in speed between $320 \mathrm{~m} / \mathrm{s}$ and $350 \mathrm{~m} / \mathrm{s}$ under conditions that are typically found within the lowermost atmosphere.

Infrasound array development increased shortly after the approval of the Comprehensive Nuclear-Test-Ban Treaty (National Academy of Sciences, 2002). The treaty prompted the establishment of the International Monitoring System (IMS), which has the capability to detect clandestine nuclear explosions (McKisic, 1997). The IMS is composed of seismic, hydroacoustic, infrasound, and radionuclide station arrays. Currently, there are 60 IMS infrasound stations worldwide (Preparatory Commission for the Comprehensive Nuclear-Test-Ban Treaty Organization, 2011), and scientists at volcanoes in locations such as Antarctica, Russia, and Italy are installing their own infrasound arrays for active monitoring (Johnson and others, 2003).

Detectable infrasound events from volcanoes include explosions, open-system processes, shallow earthquakes, tremor, rockfalls, avalanches, and degassing. Each of these events has a unique characterization at an infrasonic frequency and occurs over a variety of amplitudes. Explosions typically have recorded pressures from 1 to $50 \mathrm{~Pa}$ or more depending on the proximity of the observation and the type of explosion (Fee and Matoza, 2013). Shallow earthquakes associated with degassing can have recorded pressures disturbances on the order of $0.1 \mathrm{~Pa}$ (for example, Matoza and others, 2007). A 
rockfall at Mount St. Helens had recorded signals in the near field of $\sim 15 \mathrm{~Pa}$ (Moran and others, 2008a). Monitored volcanoes can have optical or thermal cameras at numerous locations; however, the variability of the weather can obstruct views from these devices. An infrasonic signal could thus provide an alternate monitoring parameter. Where infrasound and seismic stations are colocated, coherent signals recorded in both datastreams can aid in earthquake and volcanic interpretation (Johnson and others, 2003; Moran and others, 2008b; Garces and Le Pichon, 2011). Infrasonic waves are created only when the atmosphere is stimulated, and thus a strong infrasound signal can be diagnostic for explosion or fissure detection.

This report intends to convey an overview of the installation of the new network of infrasound arrays at HVO and to provide a preliminary analysis of the capabilities of the new network. It is intended both for scientists who intend to use the infrasound data in Hawaii and also other network operators who are interested in installing new infrasound sensors.

\section{Existing Infrasound Research on Kīlauea}

The Infrasound Laboratory at the University of Hawaii (ISLA) has had infrasound station arrays installed for several years around the Island of Hawai' $i$ as part of the IMS, as well as to analyze volcanic events. The $\mathrm{Pu}^{\prime} \mathrm{u}^{\prime} \mathrm{O}^{‘} \overline{\mathrm{o}}$ crater complex, an excellent source of continuous tremor, was analyzed using two separate arrays (KIPU and MENE) to differentiate between components of the infrasonic spectrum (Matoza and others, 2010). Sharply peaked tones concentrated in the 0.6- to 0.9-Hz band may have coincided with degassing events from hollow pockets along lava tubes. A larger broadband frequency range from 0.5 to $15 \mathrm{~Hz}$ may be associated with oscillations of bubbles in the turbulent basaltic magma source under the craters that contribute to ongoing tremor. The acoustics of flow dynamics in lava-tube systems were noted through jetting, harmonic tremor, and emission of infrasound through lava tube skylights.

The Halema'uma'u vent that opened on March 19, 2008, allowed for resonances in the new cavity to constrain dimensions of the magmatic and gaseous volume through analysis of ongoing tremor (Fee and others, 2010). Degassing events were correlated to very long period (VLP), long period (LP), and short period (SP) seismic energy at wavelengths of $0.1-0.3 \mathrm{~Hz}, 0.1-1 \mathrm{~Hz}$, and $1-10 \mathrm{~Hz}$, respectively. A camera deployed at HVO captured the opening and subsequent changes to the Halema'uma'u vent, including rockfalls and degassing bursts that ultimately widened the vent. Array processing was completed in the ranges $0.5-10 \mathrm{~Hz}$ and $0.3-1 \mathrm{~Hz}$ to construct a probability density function of the power spectral density that would highlight resonance peaks.

The March 6, 2011, Kamoamoa fissure eruption consisted of lava fountaining and jetting at remote locations within Hawai'i Volcanoes National Park. The back azimuth of the signal from the MENE array was used to determine the precise fissure locations. The signal was also used to track the temporal evolution of those fissures (Badger and others, 2012). Recorded signals associated with the jetting often exceeded $1 \mathrm{~Pa}$.

Seismic tremor is often associated with unrest and eruptions, but the occurrence of seismic tremor alone does not guarantee an eruption at the surface (Moran and others, 2008b). Conversely, infrasonic tremor only occurs when there is a disturbance at the surface and thus can be uniquely tied to eruptive processes that expel mass into the atmosphere. Together, infrasound and seismic tremor can be interpreted to understand eruptive processes at all types of volcanoes (Fee and Matoza, 2013). In remote areas that often have poor instrumentation, infrasound arrays could provide real-time data and locations where human access is difficult, if not impossible (De Angelis and others, 2012). When coupled with other sources of information outside seismology, infrasound can be a useful tool in refining our understanding of volcanic conditions and activity. 


\section{The Hawaiian Volcano Observatory Arrays}

\section{Station Hardware}

Instrumentation for each station includes a differential pressure sensor with a reference port fitted with a very low pass filter $(0.0125 \mathrm{~Hz})$ on port 1 , whereas port 2 is open to the atmosphere (fig. 1). The filter is a rigid chamber connected to the atmosphere through a very fine needle. This assembly acts in a similar manner as an electronic resistor-capacitor (RC) filter. Infrasound signals in the atmosphere constitute a pressure change on port 2 that is measured in Pascals $(\mathrm{Pa})$. Enclosed in a rigid plastic housing, the sensor is connected through a rigid hose to a screened inlet that is buried in washed gravel $3 / 4-1$ inch in diameter, contained in a 5-gallon bucket (figs. 2, 3). Each sensor is connected to a central digitizer through a small box that consolidates the four infrasound sensors into a single cable. Each infrasound array has a collocated seismometer. In addition to the gravel, station protection and noise reduction is improved by a fake rock enclosure. No lightning protection is in place. To further reduce wind noise, each sensor is sited inside a bush or deep within the rainforest, depending on the landscape.

This sensor design is similar to that of Jeff Johnson (oral commun., 2012), and has been modified by Rick LaHusen at the Cascades Volcano Observatory. The new implementation is called the VDP-10, which stands for Volcano Differential Pressure $10 \mathrm{mV} / \mathrm{Pa}$. The sensor is an All Sensors 1 inchD-MV differential pressure sensor coupled to a low-noise instrumentation amplifier with a gain of 1,000. The resultant sensor has a flat response to pressures between $0.0125 \mathrm{~Hz}$ and $25 \mathrm{~Hz}$ and self noise of $13.10 \mathrm{mPa}$ (root mean square). The total output of the system is approximately $100 \mathrm{~Pa} / \mathrm{V}$ where the frequency response is flat. A listing of poles, zeros, and amplification to remove the instrument response is included in table 1. All of our infrasound sensors are sampled at a rate of $40 \mathrm{~Hz}$.

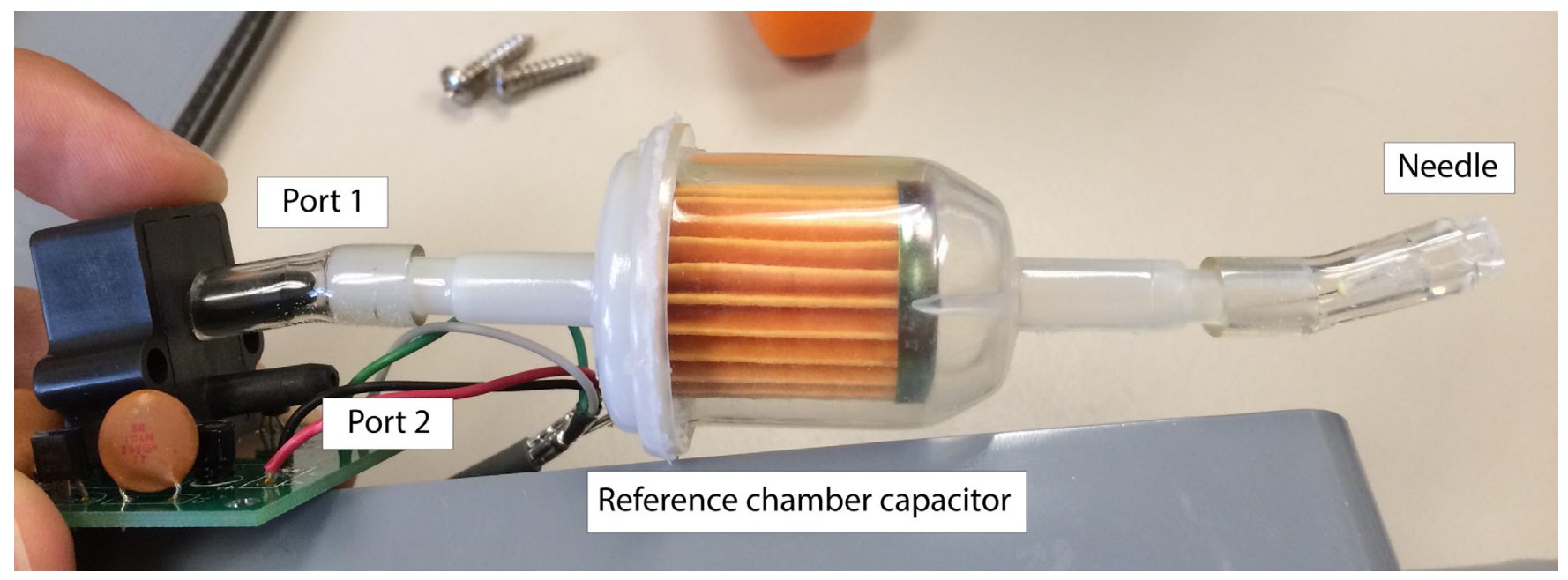

Figure 1. Photograph showing the pressure sensor instrumentation at each station. 


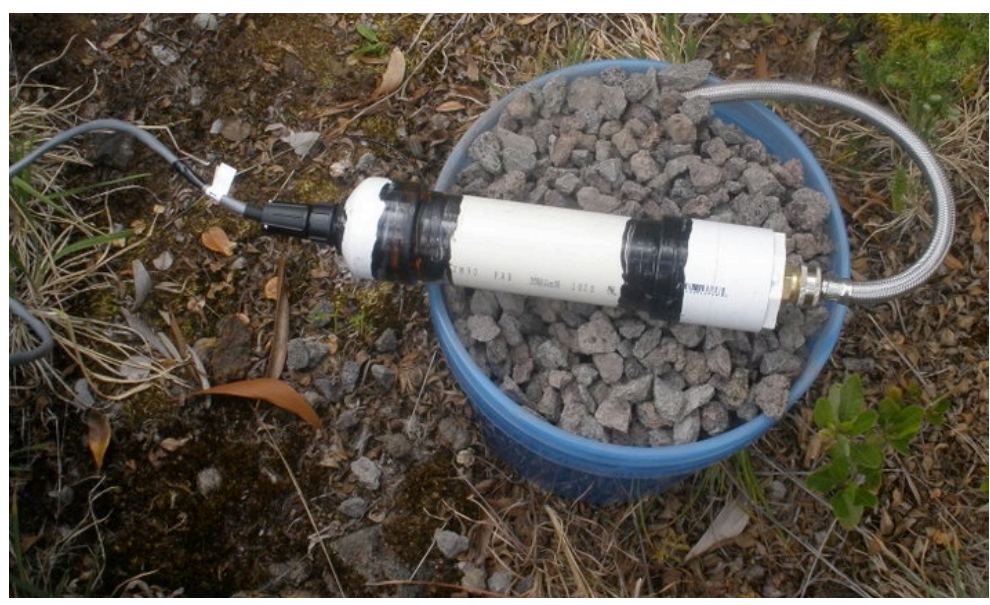

Figure 2. Photograph showing the pressure sensor enclosed in piping and resting on top of the bucket containing washed gravel and a buried screened inlet.

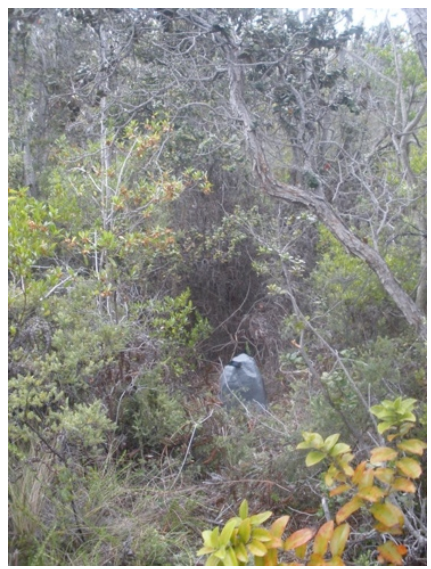

Figure 3. Photograph showing the sensor and bucket at array AIND covered with a fake rock and placed in an ideal location in the shrubbery to reduce wind noise (element 04).

Table 1. Critical sensor parameters for removing the instrument response of the infrasound sensors operated by the Hawaiian Volcano Observatory (HVO) on the Island of Hawai'i. [Two poles and one zero are present]

\begin{tabular}{|l|c|c|}
\hline & Real part & Imaginary part \\
\hline Poles, hertz & $-157.08,-0.07430195$ & 0,0 \\
\hline Zeros, hertz & 0 & 0 \\
\hline Amplification & \multicolumn{2}{|c|}{$1.56115 \mathrm{~V} / \mathrm{Pa}$} \\
\hline
\end{tabular}




\section{Location}

The ongoing eruption at Kîlauea has prompted the inclusion of advanced methods to interpret volcanic activity around the island, one of which is infrasound. The observatory already uses a dense seismic, GPS, tilt, gas, and webcam network to analyze Hawaiian volcanoes. There are now 12 infrasound elements that constitute 3 arrays; AHUD and AIND are colocated at preexisting seismometers, while HAPU is a new infrasound and seismic station (fig. 4, table 1). The AHUD array is $\sim 4 \mathrm{~km}$ south of Halema'uma' $\mathrm{u}$ Crater, while AIND and HAPU are $\sim 19 \mathrm{~km}$ west and east of Halema'uma' $u$, respectively. The HAPU array is located $\sim 3 \mathrm{~km}$ north of $\mathrm{Pu} \mathrm{u}^{\prime} \mathrm{u}$ ' $\overline{\mathrm{O}}^{`} \mathrm{o}$ so that there is widespread coverage of island activity including Mauna Loa and Kīlauea’s lower East Rift Zone and Southwest Rift Zone (table 2).

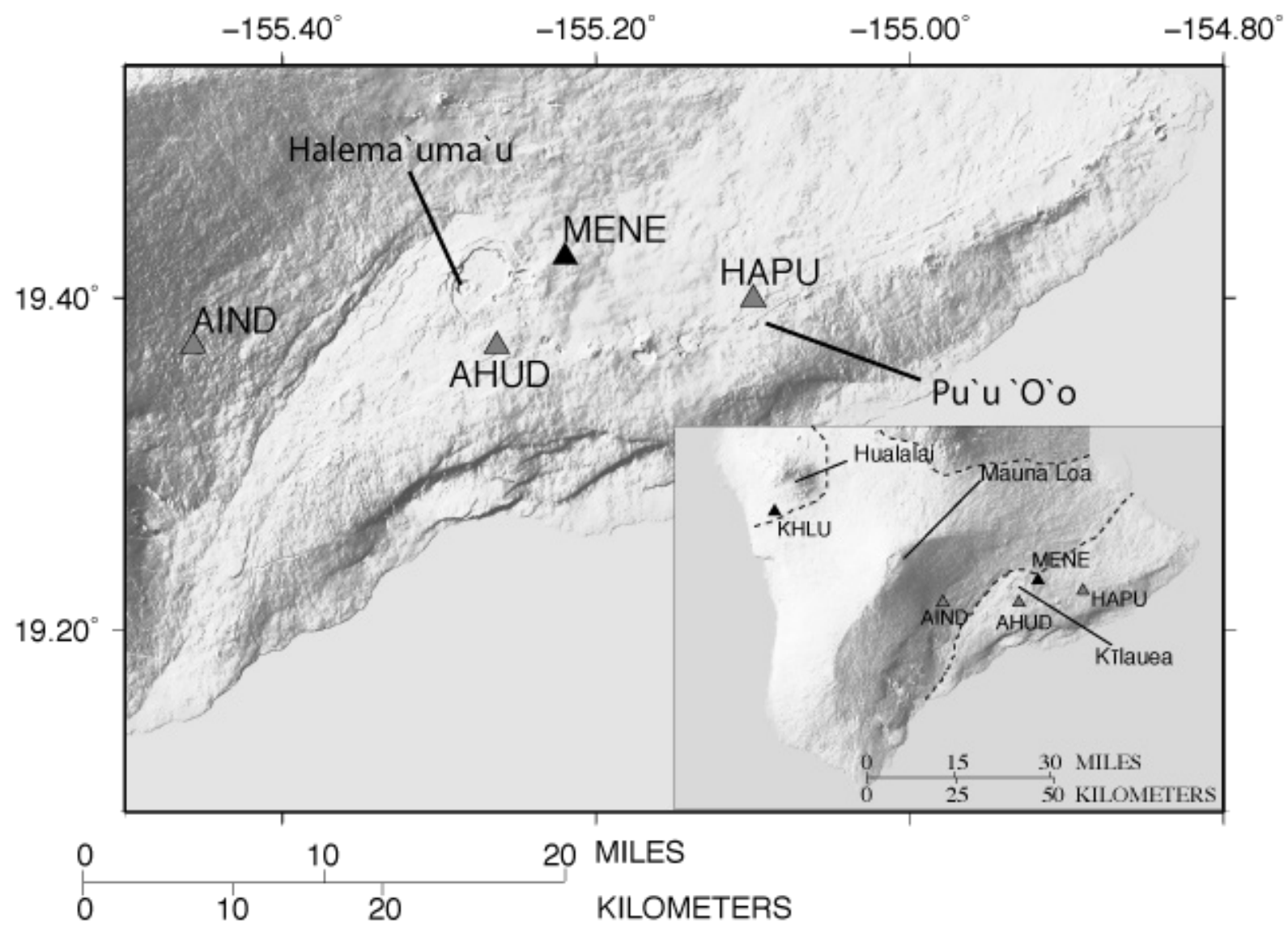

Figure 4. Map showing the arrays operated by the Hawaiian Volcano Observatory (HVO) (gray triangles), located on the southern part of the Island of Hawai'i. The MENE and KHLU arrays (black triangles) are infrasonic arrays operated by the Infrasound Laboratory at the University of Hawaii (ISLA) and monitored by HVO in real time. Individual volcanoes are delineated by dotted lines in the map inset. 
Table 2. Precise locations of infrasound stations and time of deployment on the Island of Hawai'i.

\begin{tabular}{|c|c|c|c|c|c|}
\hline Array & Element & Latitude $(\mathrm{N})$ & Longitude (W) & Elev (km) & Installation date (UTC) \\
\hline AHUD & 01 & 19.371500 & -155.26340 & 1.08 & 9/20/2012 21:16:47 \\
\hline AHUD & 02 & 19.371840 & -155.26347 & 1.0805 & 9/20/2012 21:16:47 \\
\hline AHUD & 03 & 19.371370 & -155.26285 & 1.0796 & 9/20/2012 21:16:46 \\
\hline AHUD & 04 & 19.371195 & -155.26388 & 1.0753 & 9/20/2012 21:16:47 \\
\hline AIND & 01 & 19.372062 & -155.45717 & 1.5538 & $7 / 19 / 201223: 16: 32$ \\
\hline AIND & 02 & 19.372244 & -155.45771 & 1.5481 & $7 / 19 / 201223: 16: 36$ \\
\hline AIND & 03 & 19.372158 & -155.45680 & 1.5426 & $7 / 19 / 201223: 16: 26$ \\
\hline AIND & 04 & 19.371567 & -155.45741 & 1.5483 & $7 / 19 / 2012$ 23:16:26 \\
\hline HAPU $^{1}$ & 01 & 19.416011 & -155.10156 & 0.7346 & $7 / 19 / 201223: 16: 37$ \\
\hline HAPU $^{1}$ & 02 & 19.416370 & -155.10202 & 0.7420 & $7 / 19 / 201223: 16: 34$ \\
\hline HAPU $^{1}$ & 03 & 19.416224 & -155.10111 & 0.7375 & $7 / 19 / 201223: 16: 27$ \\
\hline HAPU $^{1}$ & 04 & 19.415662 & -155.10173 & 0.7377 & $7 / 19 / 201223: 16: 30$ \\
\hline $\mathrm{MENE}^{2}$ & 01 & 19.425587 & -155.21944 & 1.04 & $3 / 30 / 2004$ \\
\hline $\mathrm{MENE}^{2}$ & 02 & 19.425881 & -155.22014 & 1.0468 & $3 / 30 / 2004$ \\
\hline $\mathrm{MENE}^{2}$ & 03 & 19.425660 & -155.21957 & 1.0362 & $3 / 30 / 2004$ \\
\hline $\mathrm{MENE}^{2}$ & 04 & 19.435270 & -155.22026 & 1.0407 & $3 / 30 / 2004$ \\
\hline $\mathrm{KHLU}^{2}$ & 01 & 19.591460 & -155.89358 & 0.958 & $11 / 25 / 2004$ \\
\hline $\mathrm{KHLU}^{2}$ & 02 & 19.591591 & -155.89356 & 0.958 & $11 / 25 / 2004$ \\
\hline $\mathrm{KHLU}^{2}$ & 03 & 19.591429 & -155.89352 & 0.958 & $11 / 25 / 2004$ \\
\hline $\mathrm{KHLU}^{2}$ & 04 & 19.591372 & -155.89369 & 0.958 & $11 / 25 / 2004$ \\
\hline
\end{tabular}

${ }^{1}$ The HAPU array was uninstalled on June 15, 2012, because of an advancing lava flow.

${ }^{2}$ The MENE and KHLU arrays are operated by the Infrasound Laboratory at the University of Hawaii (ISLA) and are included for completeness.

Table 3. Infrasound arrays with the expected back azimuth, distance, and travel time to important sources across the Island of Hawai'i.

[Sound speed assumed to be $340 \mathrm{~m} / \mathrm{s}$ ]

\begin{tabular}{|c|c|c|c|c|c|c|c|c|c|}
\hline \multirow[b]{2}{*}{ Array } & \multicolumn{3}{|c|}{ Halema'uma'u } & \multicolumn{3}{|c|}{ Pu‘u ‘ō‘ō } & \multicolumn{3}{|c|}{ Mauna Loa Summit } \\
\hline & $\begin{array}{c}\text { Back } \\
\text { azimuth } \\
\left(^{\circ}\right)\end{array}$ & $\begin{array}{c}\text { Distance } \\
\quad(\mathbf{k m})\end{array}$ & $\begin{array}{c}\text { Travel } \\
\text { time (s) }\end{array}$ & $\begin{array}{c}\text { Back } \\
\text { azimuth } \\
\left(^{\circ}\right)\end{array}$ & $\begin{array}{c}\text { Distance } \\
\quad(\mathbf{k m})\end{array}$ & $\begin{array}{c}\text { Travel } \\
\text { time (s) }\end{array}$ & $\begin{array}{c}\text { Back } \\
\text { azimuth } \\
\left({ }^{\circ}\right)\end{array}$ & $\begin{array}{c}\text { Distance } \\
\quad(\mathbf{k m})\end{array}$ & $\begin{array}{c}\text { Travel } \\
\text { time (s) }\end{array}$ \\
\hline AHUD & 334 & 4 & 12 & 83 & 17 & 49 & 288 & 36 & 106 \\
\hline AIND & 79 & 19 & 56 & 87 & 37 & 109 & 309 & 17 & 50 \\
\hline HAPU & 266 & 19 & 55 & 187 & 3 & 9 & 277 & 52 & 153 \\
\hline MENE $^{1}$ & 252 & 7 & 21 & 109 & 13 & 38 & 277 & 41 & 121 \\
\hline $\mathrm{KHLU}^{1}$ & 107 & 68 & 200 & 104 & 87 & 256 & 114 & 35 & 103 \\
\hline
\end{tabular}

${ }^{1}$ The MENE and KHLU arrays are operated by the Infrasound Laboratory at the University of Hawaii (ISLA) and are included for completeness.

The arrays are designed to be a 100-m equilateral triangle with a sensor (element) at each point and one in the center (figs. 5, 6, and 7). Topography and impediments on the ground mean that this geometry is never fully realized; however, the basic layout is maintained. This method of installation is utilized because it offers spatial parameters such as back azimuth and apparent or trace velocity that a single station cannot offer. As a signal waveform crosses the array, the arrival time at each station will differ depending on the apparent speed and back azimuth, which can be inferred from the data. Similarly, the signal-to-noise ratio can be improved with this array design through coherence stacking. 


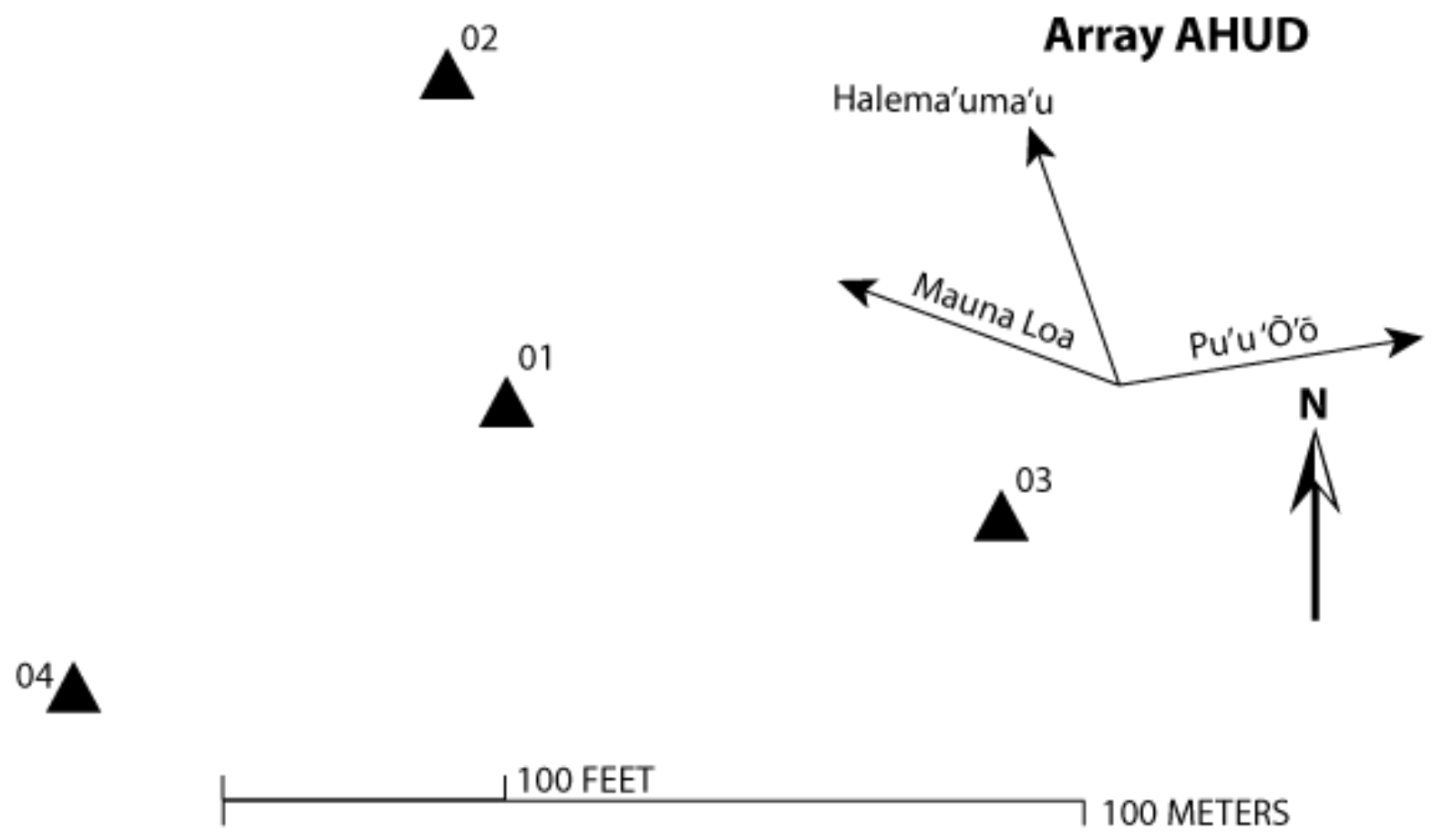

Figure 5. Plot showing the infrasound elements in the AHUD array. Numbers refer to location code of the given sensor. A seismometer is colocated with element 01 . Arrows give approximate directions to Halema'uma'u, Pu'u 'Ō'ō, and Mauna Loa Summit. 


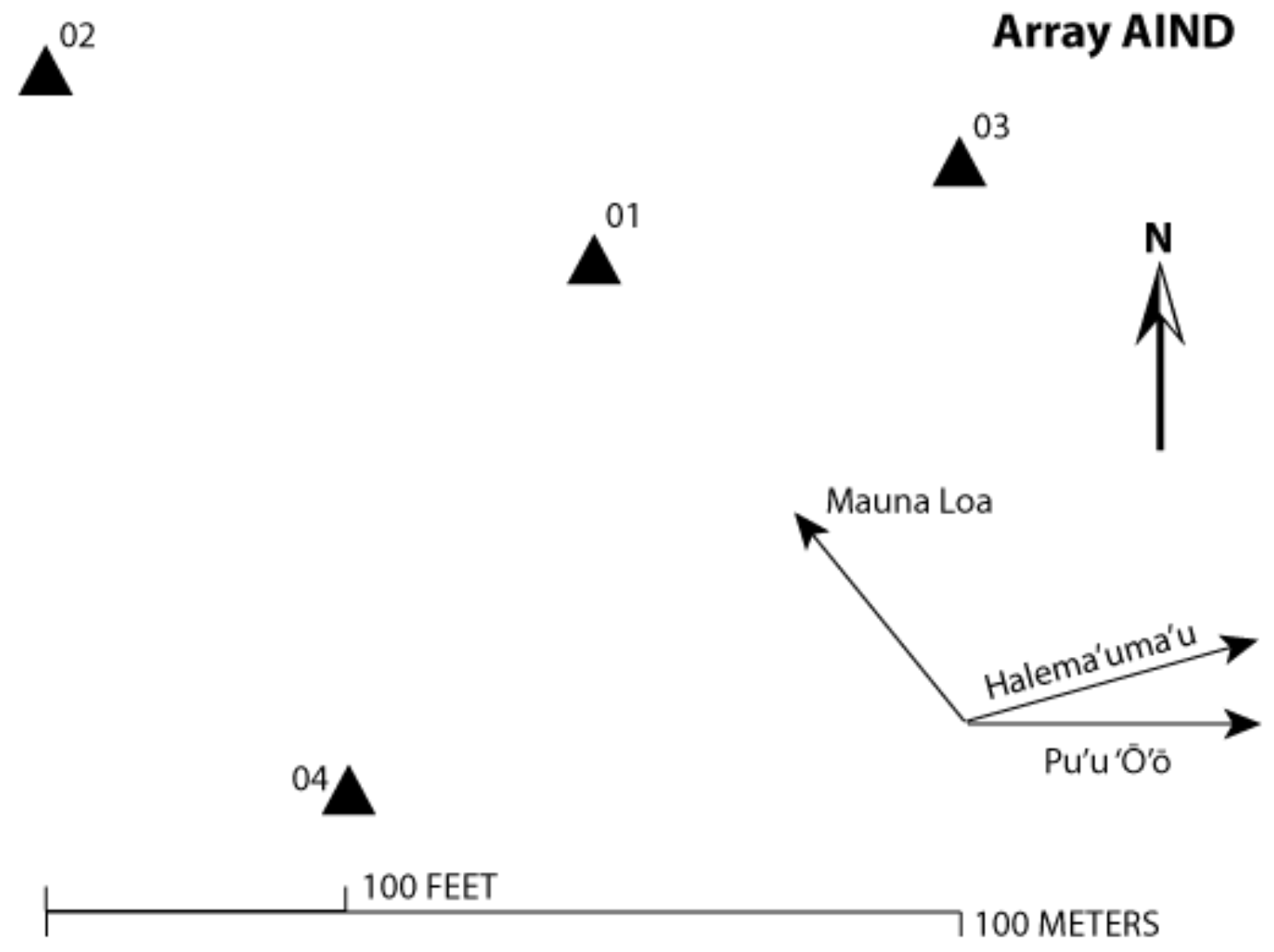

Figure 6. Plot showing the infrasound elements in the AIND array. Numbers refer to location code of the given sensor. A seismometer is colocated with element 01. Arrows give approximate directions to Halema'uma'u, Pu'u 'Ō'ō, and Mauna Loa Summit. 


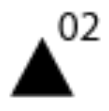

\section{Array HAPU}
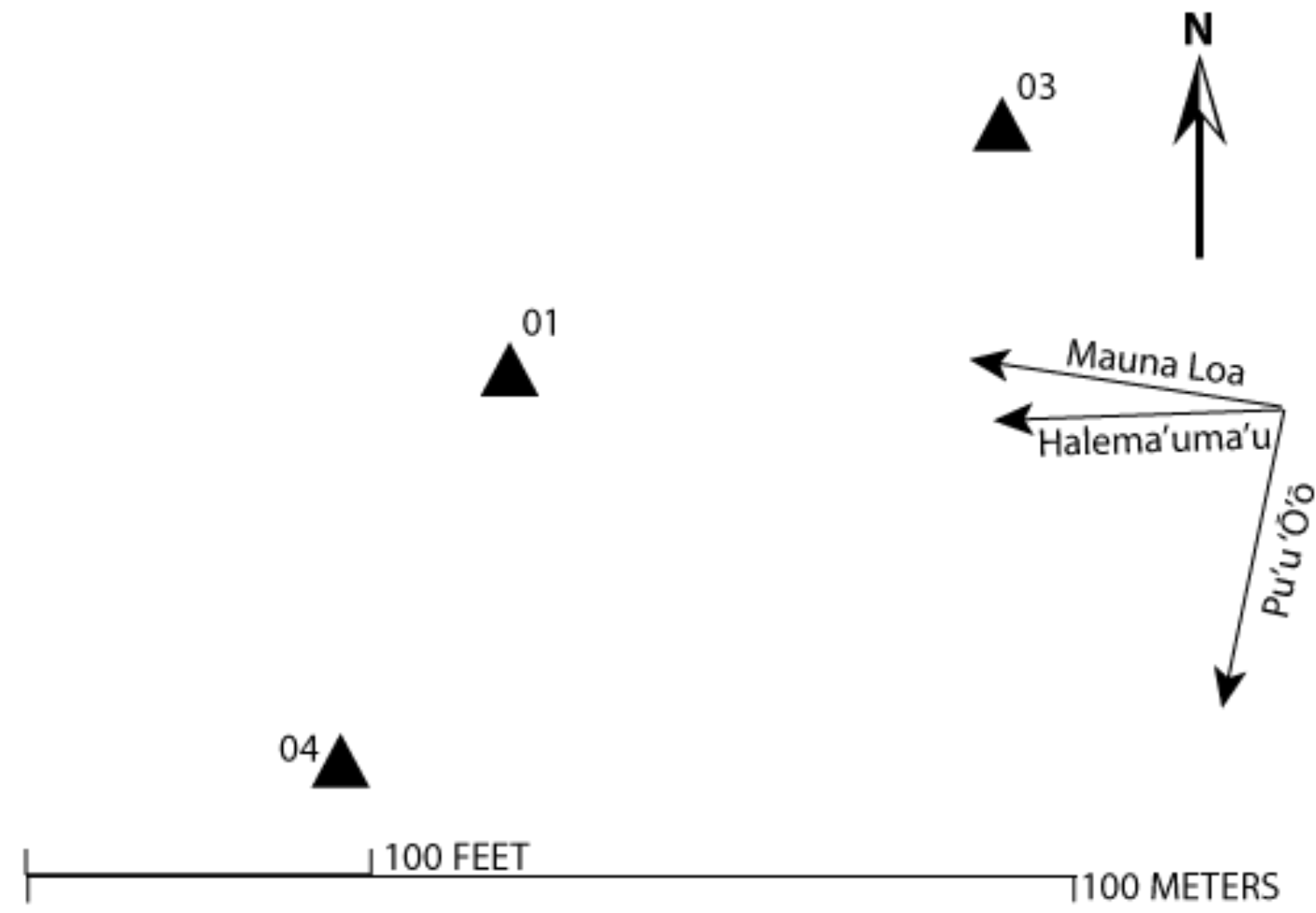

Figure 7. Plot showing the infrasound elements in the HAPU array. Numbers refer to location code of the given sensor. A seismometer is colocated with element 04. Arrows give approximate directions to Halema'uma'u, Pu'u 'Ō‘ō, and Mauna Loa Summit.

\section{Data Collection and Initial Processing}

Infrasound data must undergo a certain amount of transfer and processing in order to be further analyzed. This process is far from straightforward, so we have detailed the data flow in figure 8. Data from the four infrasound sensors at a single array are collected at a single 6-channel Reftek RT-130 digitizer. After being transmitted over a digital link to a Reftek Transfer Protocol Daemon (RTPD) server, data are transmitted into the Earthworm processing environment through a ref2ew module (http://www.isti2.com/ew/modules.html). From the Earthworm environment, data are stored in Winston wave servers (WWS) for storage and rudimentary processing. Once infrasound data enter the WWS, they are stored and archived the same as any other seismic data. The data are also exported to the Incorporated Research Institutions for Seismology (IRIS) for public consumption and long-term storage. Our Earthworm processing imports data from the MENE and KHLU arrays (operated by ISLA) in nearreal time. Imported stations are also stored in WWS. Certain processing environments require the Center for Seismic Studies (CSS) format, so we store CSS flat files as well (using Earthworm modules archman and waveman2disk). CSS flat files are kept only for a short time. The CSS flat files can be readily made from the data stored on the WWS for periods of interest that may exceed the time of our standard CSS storage. 


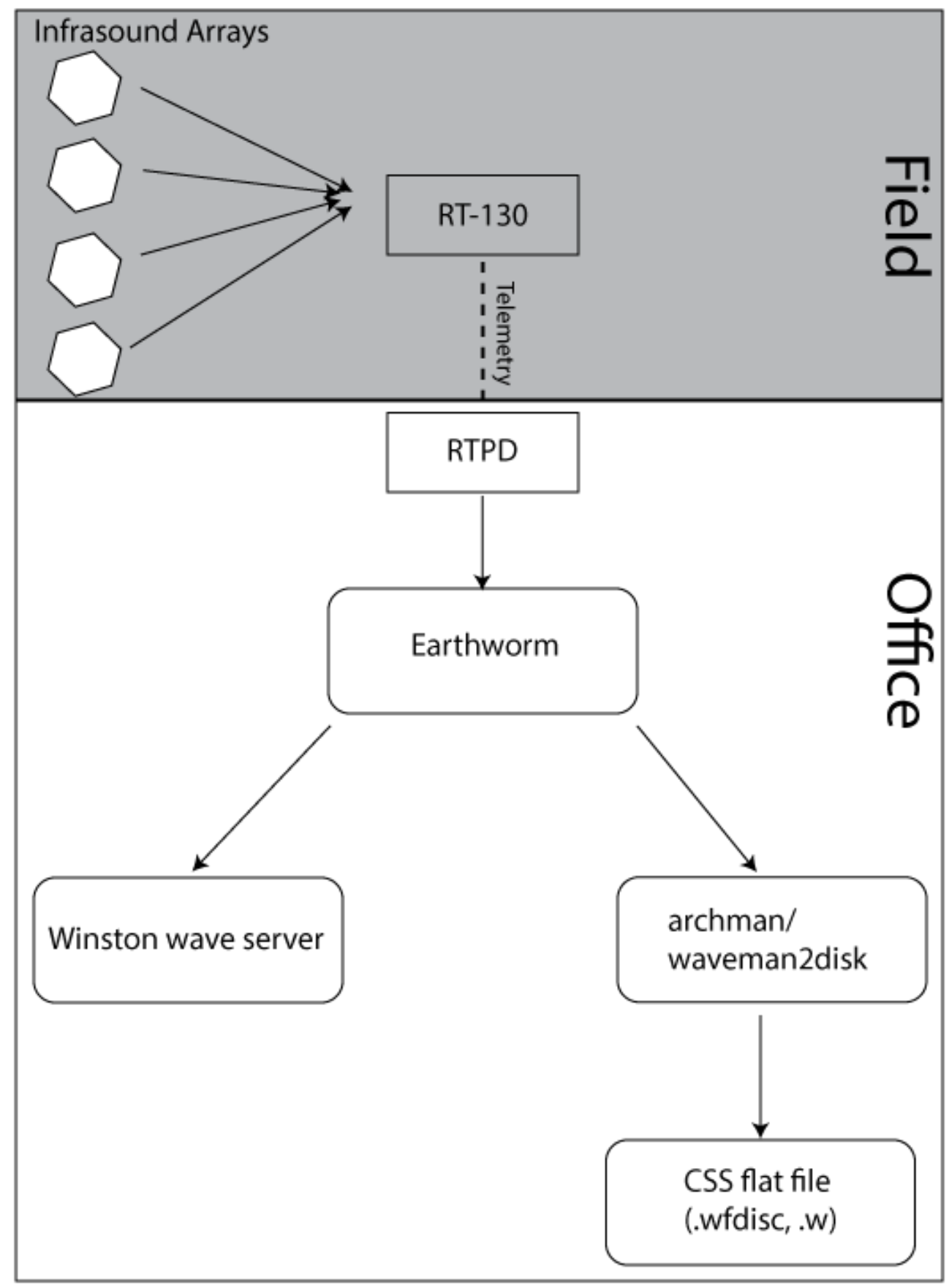

Figure 8. Flow chart detailing the path that infrasound data take before being stored. The upper and lower boxes contain those processes that are completed in the field and office, respectively. We use a Reftek model 130 digitizer (RT-130) in the field and a Reftek Transfer Protocol Daemon (RTPD) for data acquisition. 


\section{Data Analysis}

Because we use arrays in our infrasound network, our processing relies on many of the concepts of array seismology (for example, Rost and Thomas, 2002). Arrays are beneficial because the signal-tonoise ratio (which increases with the square root of the number of components) is improved and spatial information such as back azimuth and slowness (defined as $1 /$ speed) can be determined. One way to calculate the slowness and back azimuth directly is to transform the time signal into frequencywavenumber (f-k) space. The f-k methods are described in Aki and Richards (2002), and this method is implemented in the ObsPy package (Beyreuther and others, 2010) as the function sonic. Our analysis using this technique uses the full bandwidth of the signal. In practice, this meant that detections were only achieved with large broadband infrasonic transients such as vent collapses at Halema'uma'u (see "Case Studies Using the HVO Arrays"). Infrasonic tremor at Halema'uma'u was not easily identified using this technique.

An alternative, though complementary, method is the Progressive Multi-Channel CrossCorrection (PMCC) method (Cansi, 1995). This method uses cross-correlation of waveforms between subarrays (subsets of elements in a single array) to detect and characterize infrasonic phases, including the slowness and back azimuth of the detection. If the detection differs in back azimuth, slowness, or time between subarrays, then the detection is discarded. In our data, each array can be divided into 4 unique subarrays of three elements each. Data are also analyzed in many narrow bands to isolate specific signals. The result is a very powerful detection and analysis tool that allows a user to easily discriminate coherent signals from noise. We are encouraged by initial results obtained using the PMCC method implemented through the WinPMCC code (Le Pichon and Cansi, 2003; Le Pichon and others, 2010). Not only can the algorithm reliably detect variations in infrasonic tremor from Halema'uma' $u$, it can also detect signals from the Pōhakuloa Training Area on the north side of Mauna Loa. Given our array geometry and quality results from the PMCC method, it seems a natural step to calculate triangulated locations in near-real time.

\section{Noise}

Each site has particular environmental and anthropogenic activity that influences the background noise. A main source of nearly constant noise at these stations is wind; around the Kîlauea Volcano, trade winds generally blow from the northeastern direction at a range of $4-7 \mathrm{~m} / \mathrm{s}$. Wind is the most common source of noise at frequencies above $0.5 \mathrm{~Hz}$ (Bowman and others, 2005). Other variable infrasonic sources in the region include oceanic movements that create frequencies between 0.1 and 0.5 $\mathrm{Hz}$, often called the microbarom (Arendt and Fritts, 2000), automobiles, airplanes, and the Pōhakuloa Training Area (on the northwest flank of Mauna Loa) used by the U.S. Army. Bombing in this area produces a strong signal that is detected at AIND at $\sim 270^{\circ}$. Topographic distortion of the infrasound signal over Mauna Loa was shown by Garces and Le Pichon (2011). The HAPU array occasionally has a small signal at a back azimuth of $0-24^{\circ}$, which could be originating from the town of Volcano or Hilo, Hawaii. To analyze the noise at each array, we typically calculate a probabilistic power spectral density or PPSD (McNamara and Buland, 2004) for each element of each array. Current PPSD functions for each station are available at IRIS (http://www.iris.edu/ds/products/pdf-psd), where the data are archived and available to the public. 


\section{Case Studies Using the HVO Arrays}

\section{Data Processing}

The Hawaiian Volcano Observatory is currently monitoring two open vents on Kîlauea Volcano that have had infrasound-detectable events. The lava lakes at Halema'uma'u Crater and $\mathrm{Pu}^{`} \mathrm{u}{ }^{\prime} \mathrm{O}^{`} \bar{o}$ produce a variety of activity, which was analyzed in the three case studies below. Data analysis is accomplished with the sonic function of ObsPy and the Progressive Multi-Channel Correlation (PMCC) method using WinPMCC software. Frequency-wavenumber ( $\mathrm{f}-\mathrm{k})$ analysis in ObsPy produces two plots: (1) a time series of the wave propagation's relative power compared to background noise, absolute power, back azimuth, and slowness; and (2) a polar plot that shows the signal intensity and its direction based on relative power. We only show polar plots in this report.

The PMCC also allows for a full array analysis but includes tools to mask various components of an incoming waveform based on direction, power, speed, and time. This can create a filter for unwanted noise and allow for more discrete analysis on a coherent signal. These capabilities are also possible with the results of the f-k analysis; however, they are not currently implemented.

\section{Halema'uma‘u Rockfall: October 6, 2012, 23:30:55 UTC}

This moderately sized rockfall at Kīlauea's summit in Halema'uma'u Crater was accompanied by several other similar events in the following 12 hours, all of which had detectable, coherent seismic signals correlated with visual observations of wall collapses in the crater. The rockfall analyzed here originated from the northwestern wall and impacted the lava lake, which created small explosive events and spatter (fig. 9). At that time, it was estimated that the lava lake was $\sim 50 \mathrm{~m}$ below the crater floor, which translates to $\sim 130 \mathrm{~m}$ from the webcam.
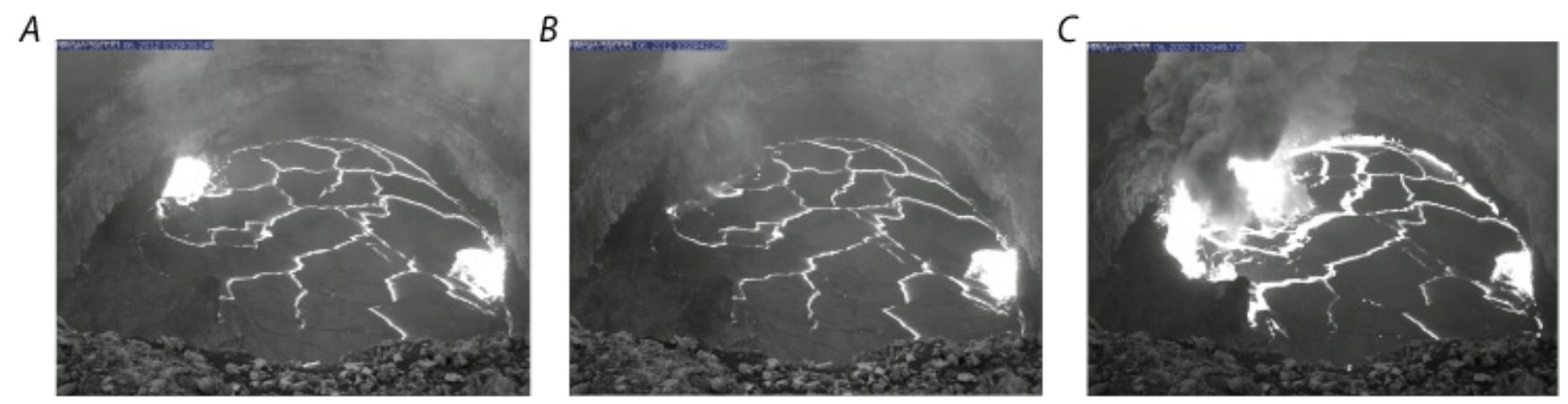

Figure 9. Photographs showing the rockfall event at Halema'uma'u Crater on October 6, 2012. A, Halema'uma'u lava lake before the rockfall at 23:29:38.148 UTC. There are two spatter zones at the west (left) and east (right) areas of the crater. $B$, The rockfall occurred on the western part of the crater (left side of the image) over the west spatter area at 23:29:42.258 UTC. $C$, As the rock lands in the lava lake, it creates a large spatter and debris plume at 23:29:49.730 UTC. The lava lake experiences a wave-like motion from the impact, and some lava is pushed up onto the southwestern ledge in the left corner of the frame. 
Both AHUD and AIND recorded distinct infrasonic signals from the rockfall event, but HAPU only weakly recorded the rockfall (fig. 10). Using the raw signal, the f-k analysis shows positive identifications on AHUD and AIND and a poor identification on HAPU (fig. 11). Amplitudes of the stacked signals on the AHUD, AIND, and HAPU arrays were approximately $0.65 \mathrm{~Pa}, 0.065 \mathrm{~Pa}$, and $0.05 \mathrm{~Pa}$, respectfully. For a majority of similar rockfall events, the HAPU array does not obviously detect signals from the summit. A more detailed view of the event at the three arrays was calculated with WinPMCC (figs. 12-15). Wind speeds varied during the event from 3-4 m/s, and wind direction was from the south $\left(\sim 156^{\circ}\right)$.

One clear result from the analysis of this infrasound signal is the greater utility of arrays compared to single sensor (element) installations. The rockfall from Halema'uma'u was relatively small, particularly with respect to signals typically recorded during a breakout or stratovolcanic eruption. Even so, two arrays that were nearly $20 \mathrm{~km}$ away from the source were able to detect the signal with enough fidelity to get azimuthal information. Having single elements at each of those sites would not have provided the same information. It is also important to note that these signals were not easily seen in the raw signal.

Our analysis also compares results of two different processing schemes. Comparison of figure 11 and figure 15 shows that the spatial processing employed by the PMCC method can be more precise and sensitive to high frequency transients associated with rockfall than the traditional f-k method as implemented in ObsPy. The histograms calculated with PMCC (fig. 15) have higher signal-to-noise ratios closer to the expected azimuth than those polar plots calculated by the f-k method (fig. 11). 


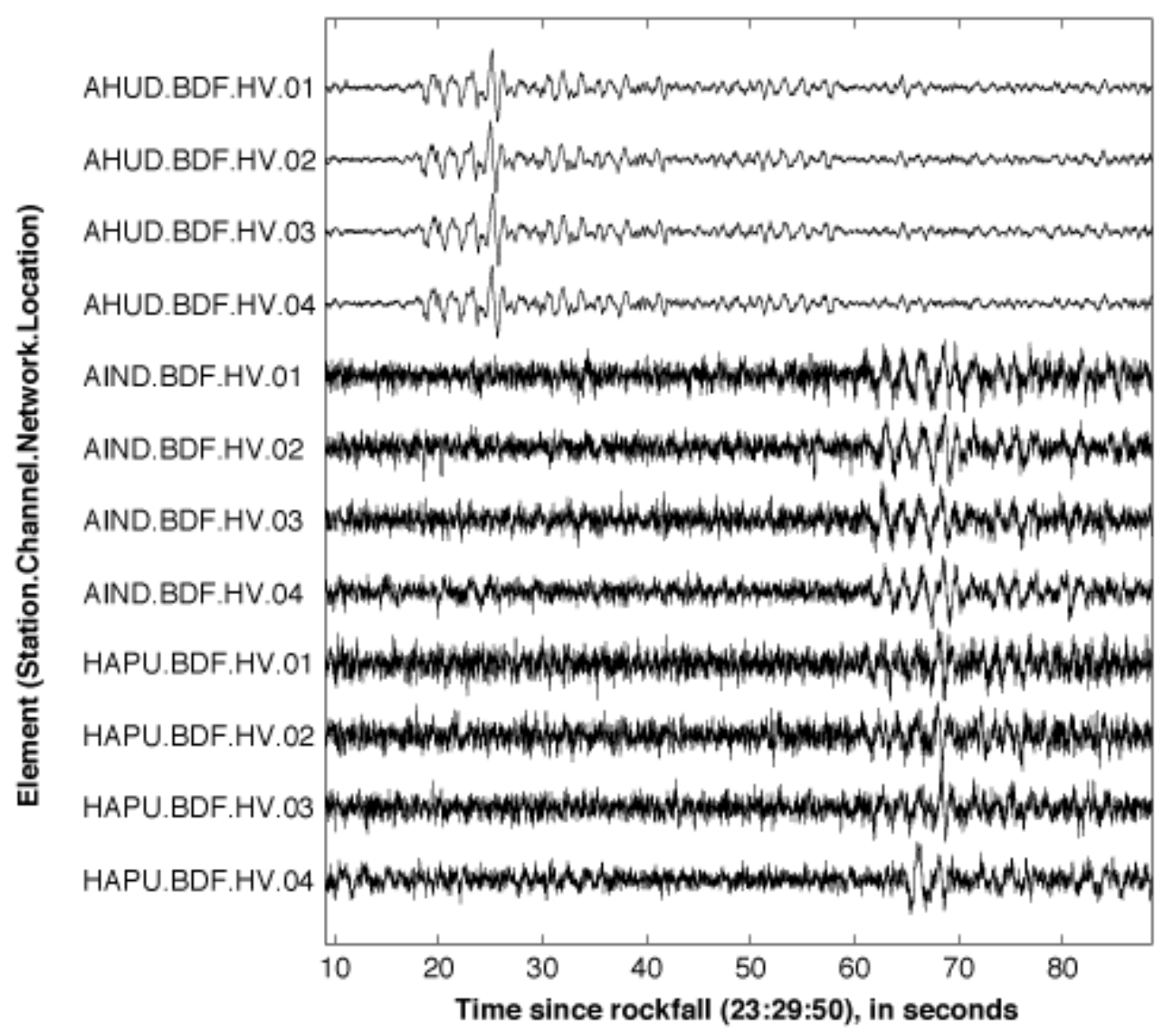

Figure 10. Graph showing infrasound waveforms from the Halema'uma'u rockfall filtered above the microbarom $(0.4 \mathrm{~Hz})$. The signal first appears at the AHUD array at 18 seconds after the rockfall, then at $\sim 62$ seconds after the rockfall at the AIND array. The rockfall is only weakly recorded at the HAPU array between 60 and 70 seconds after the rockfall. The signal at HAPU is not visible in the raw signal. 

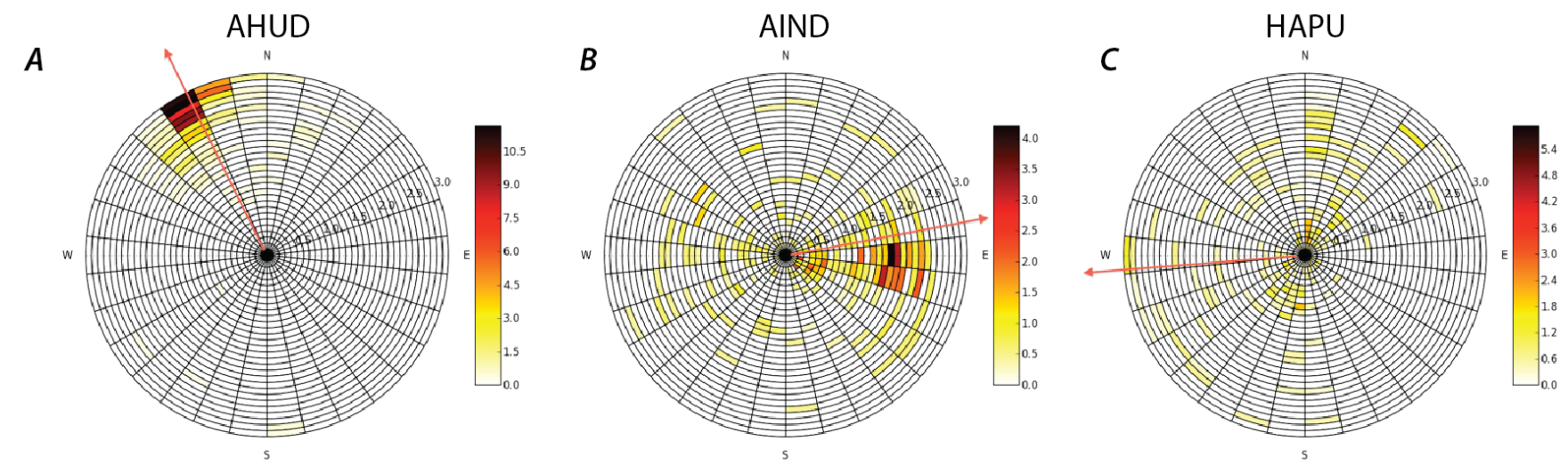

Figure 11. Polar plots showing $\mathrm{f}-\mathrm{k}$ analysis of the Halema'uma'u rockfall at three infrasound arrays. A, AHUD. B, AIND. C, HAPU. Colored boxes indicate where energy is detected. Slowness increases outward on the polar plot between 0 (center, vertically incident) and 3 $\mathrm{s} / \mathrm{km}$ (outer edge). The azimuth of the colored box represents the back azimuth. Expected back azimuths (red arrows) at the AHUD, AIND, and HAPU arrays are $334^{\circ}, 79^{\circ}$, and $266^{\circ}$, respectively. Note the differing color scales in each plot. 


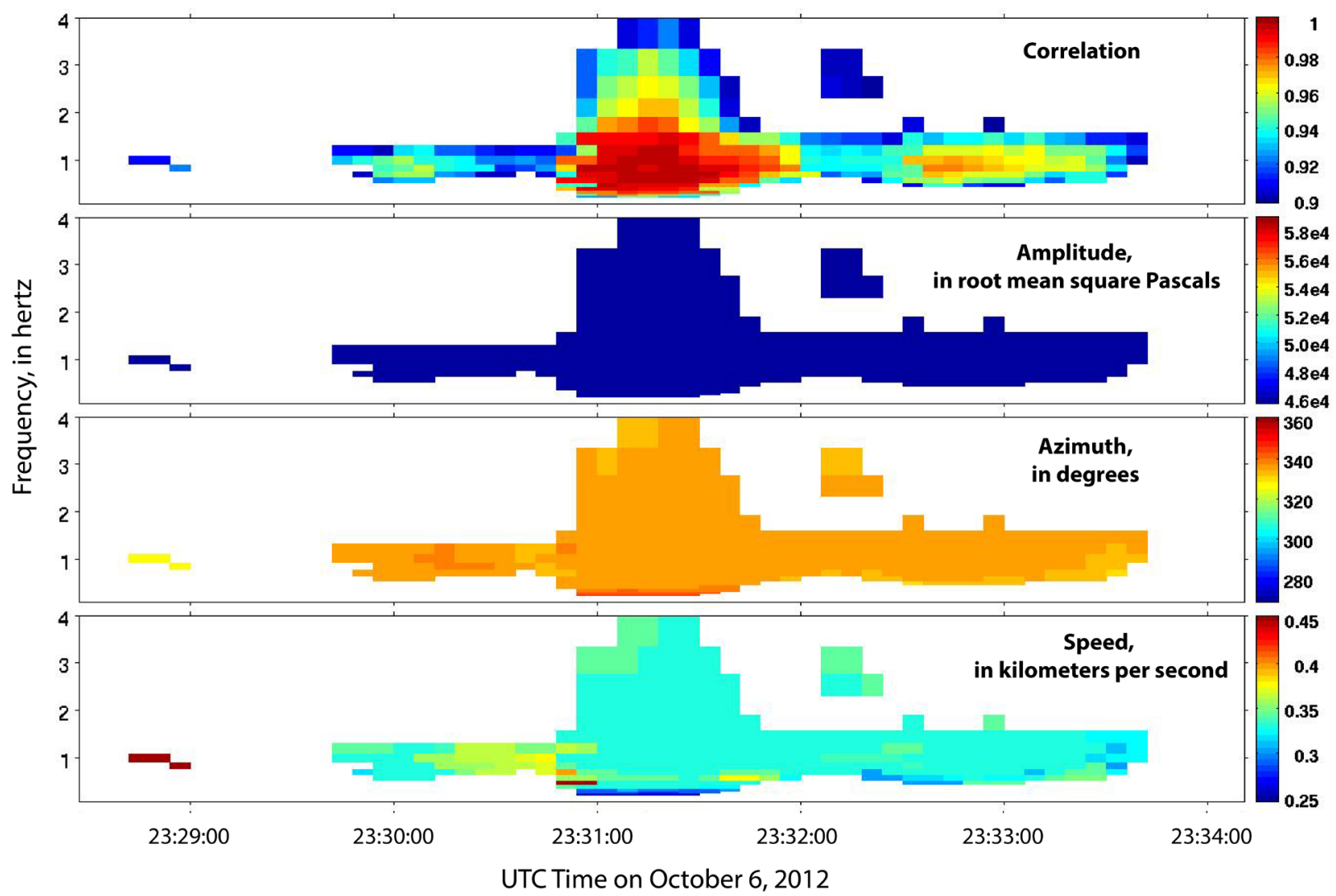

Figure 12. Graphs showing PMCC analysis of the Halema'uma'u rockfall at the AHUD array. Only detections with a correlation coefficient of 0.9 or greater are shown. The correlation refers to the consistency of the waveform between array elements. The amplitude is the averaged amplitude across the array. Azimuth refers to the direction that the wave is originating from, and speed refers to the speed of the event across the array. The filtered event waveforms from AHUD are shown in figure 10. 


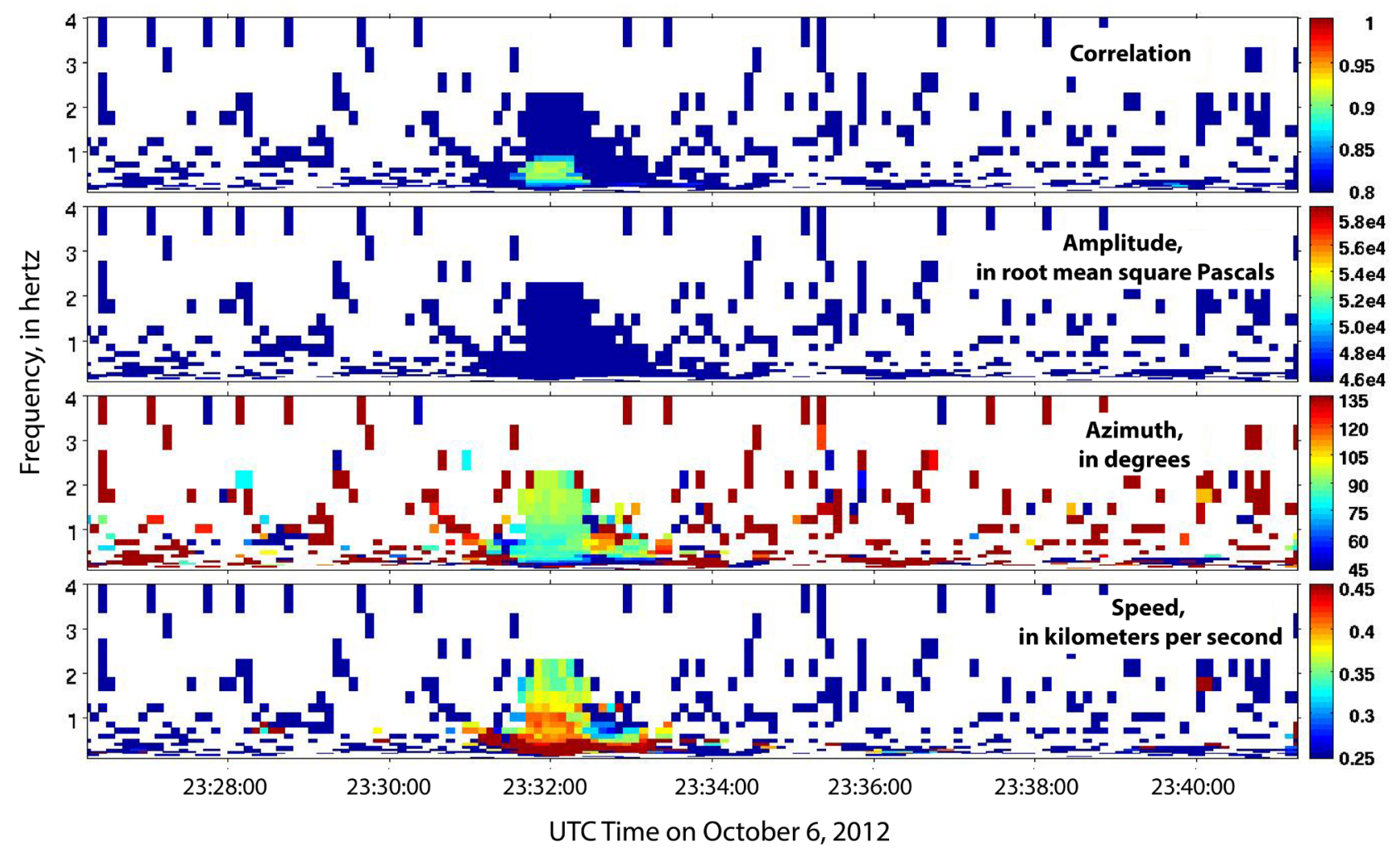

Figure 13. Graphs showing PMCC analysis of the Halema'uma'u rockfall at the AIND array. Only signals with a correlation of 0.8 or greater are shown. The rockfall is the obvious signal around 23:32:00 UTC. The filtered waveforms for the event are shown in figure 10. The correlation refers to the consistency of the waveform between array elements. The amplitude is the averaged amplitude across the array. Azimuth refers to the direction that the wave is originating from, and speed refers to the speed of the event across the array. 


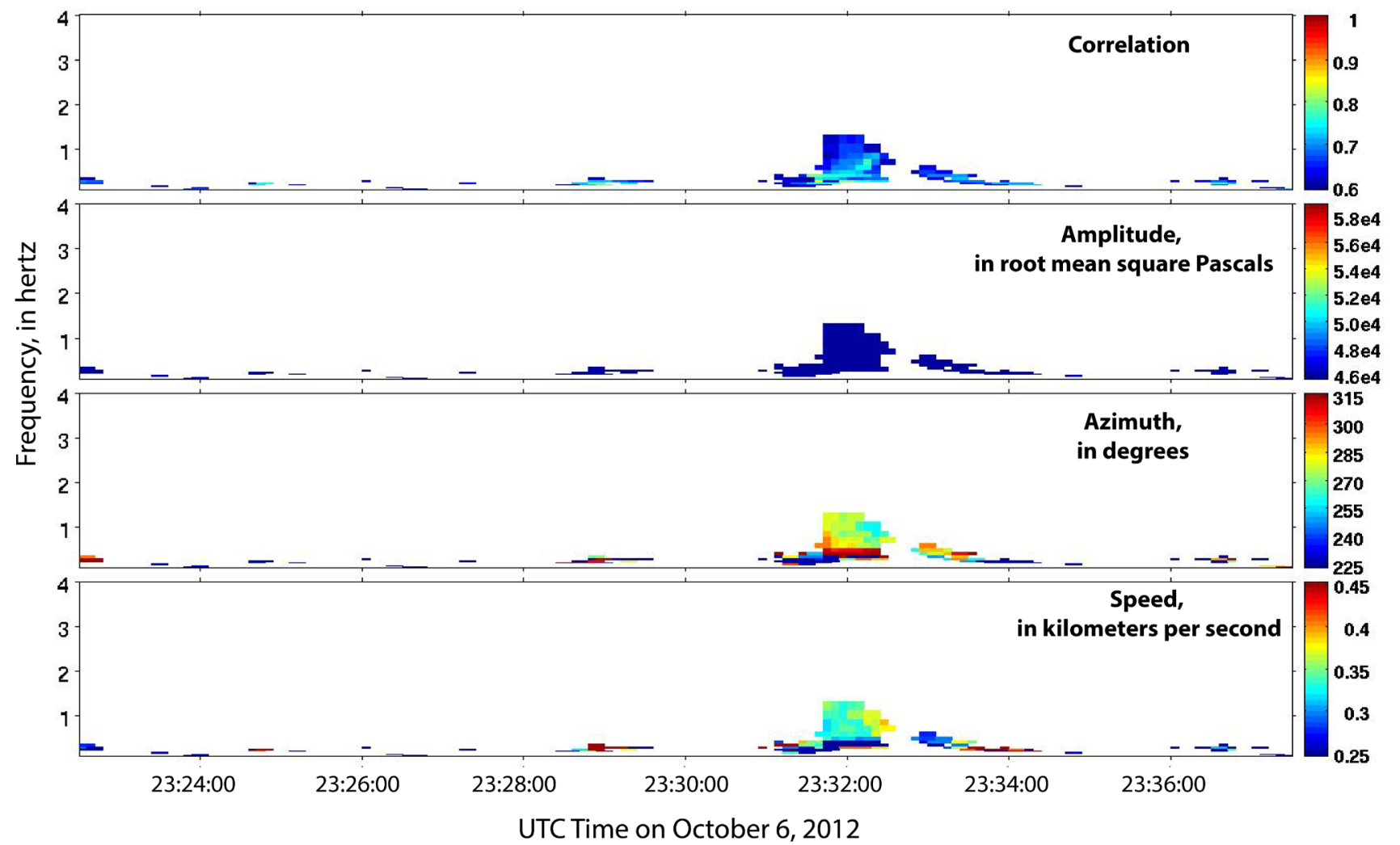

Figure 14. Graphs showing PMCC analysis of the Halema'uma'u rockfall at the HAPU array. Only signals with correlations above 0.6 are included. The rockfall is the obvious signal around 23:32:00 UTC. The filtered waveforms for the event are shown in figure 10. The correlation refers to the consistency of the waveform between array elements. The amplitude is the averaged amplitude across the array. Azimuth refers to the direction that the wave is originating from, and speed refers to the speed of the event across the array. 

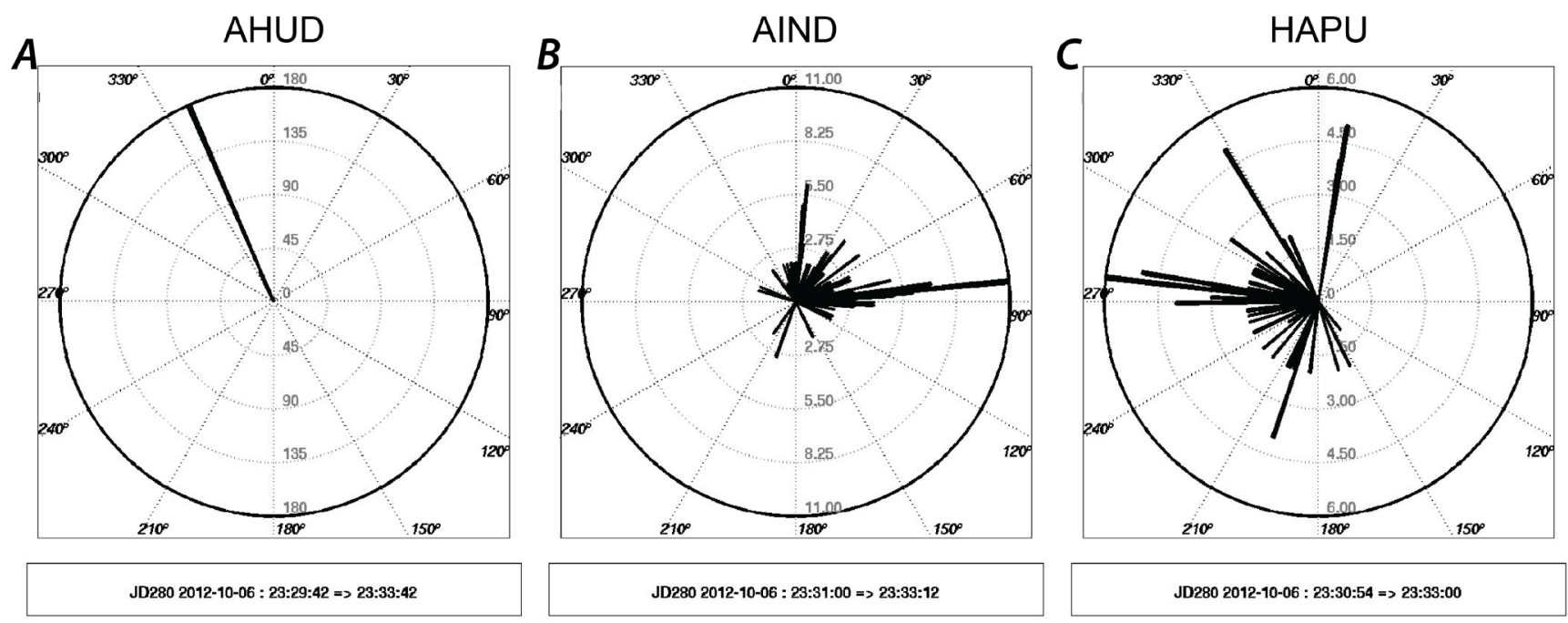

Figure 15. Histograms of the azimuth of signal detections for the PMCC analysis of the Halema'uma'u rockfall at three infrasound arrays. A, AHUD. B, AIND. C, HAPU. Times are shown in the pane at the bottom. Obvious detections are present on the AHUD and AIND arrays. The HAPU array also detects the signal; however, it's much less clear. Expected back azimuths at AHUD, AIND, and HAPU arrays are $334^{\circ}, 79^{\circ}$, and $266^{\circ}$, respectively. Note the differing lengths of the histograms, which represent the number of coherent detections in the evaluation period (gray numbers).

\section{Pu‘u ‘Ō‘ō Pit Collapse: August 30, 2012, 20:05 UTC}

In the western part of $\mathrm{Pu}^{\prime} \mathrm{u}$ ' $\overline{\mathrm{O}}^{‘} \overline{\mathrm{o}}$ Crater, a floor collapse on the north side of the crater was preceded by a similar occurrence nearly 6 hours earlier that widened the southern edge of the pit; however, the event at 20:09 UTC also produced a fuming source on the eastern boundary of the crater. Images taken via helicopter overflights are used to illustrate the pit shape before and after the collapse (fig. 16). Since this occurred before AHUD was installed, only AIND and HAPU were available; only HAPU detected the event.

The infrasound signal was fairly small, despite a strong seismic signal (fig. 17). The stacked infrasonic signal on HAPU only amounted to $0.06 \mathrm{~Pa}$. Analysis using f-k and WinPMCC yield similar azimuthal results (fig. 18). Spectrally, the signal is clearly seen between 1 and $3 \mathrm{~Hz}$ (fig. 19). The upper limit is likely due to the spacing of the stations within the array. Interestingly, there are several other detections from the direction of $\mathrm{Pu}^{\prime} \mathrm{u}$ ' $\overline{\mathrm{O}}^{\prime} \bar{o}$ both before and after the main collapse that do not have an obvious seismic signal and may be related to the northeast lava lake or the refilling of the collapse pit. 


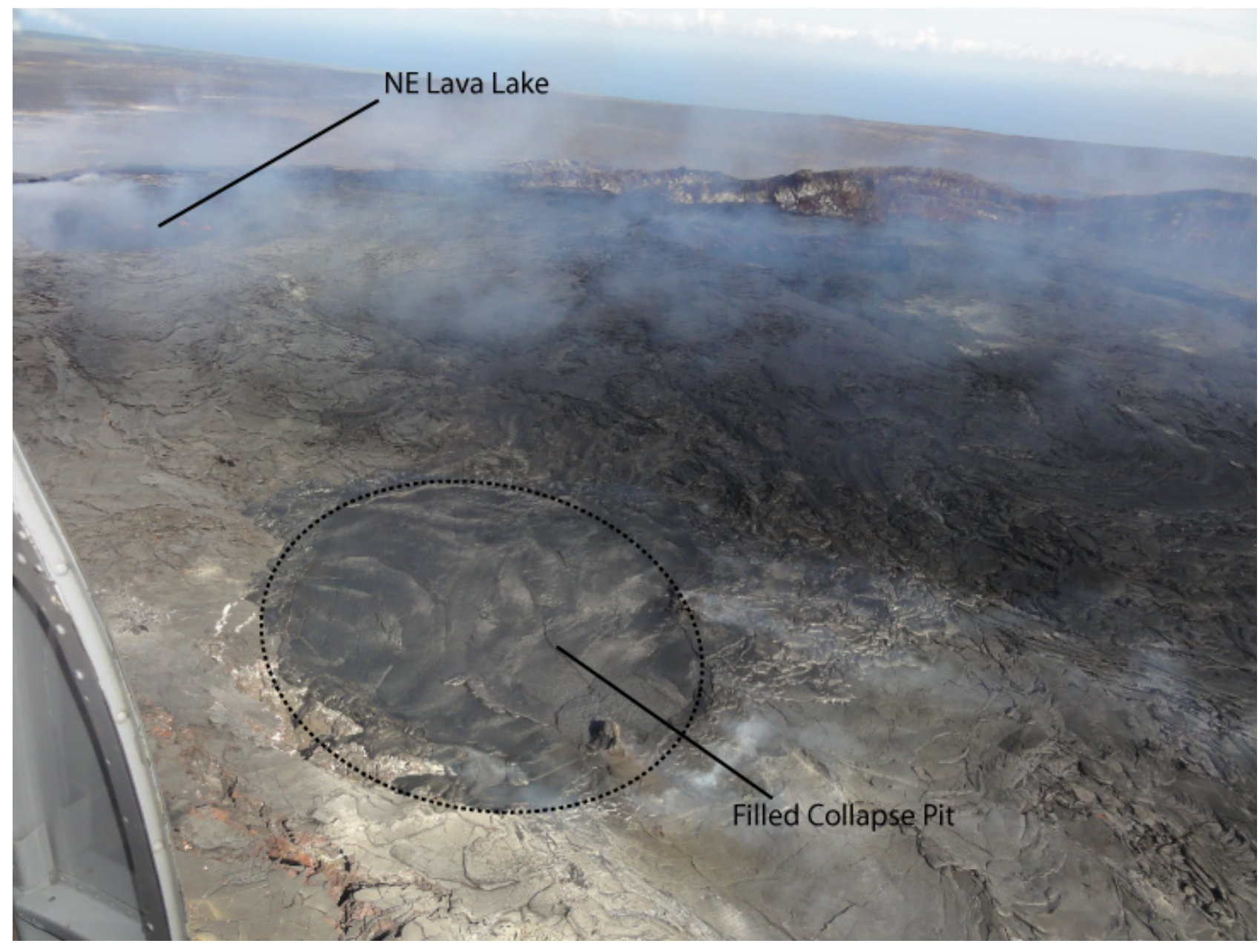

Figure 16. Aerial photo of Pu'u 'Ō'ō Crater looking east-southeast. The collapse pit (dotted ellipse) was already filled with lava at the time of this picture. The collapse pit was estimated to be 30-40 m wide. 


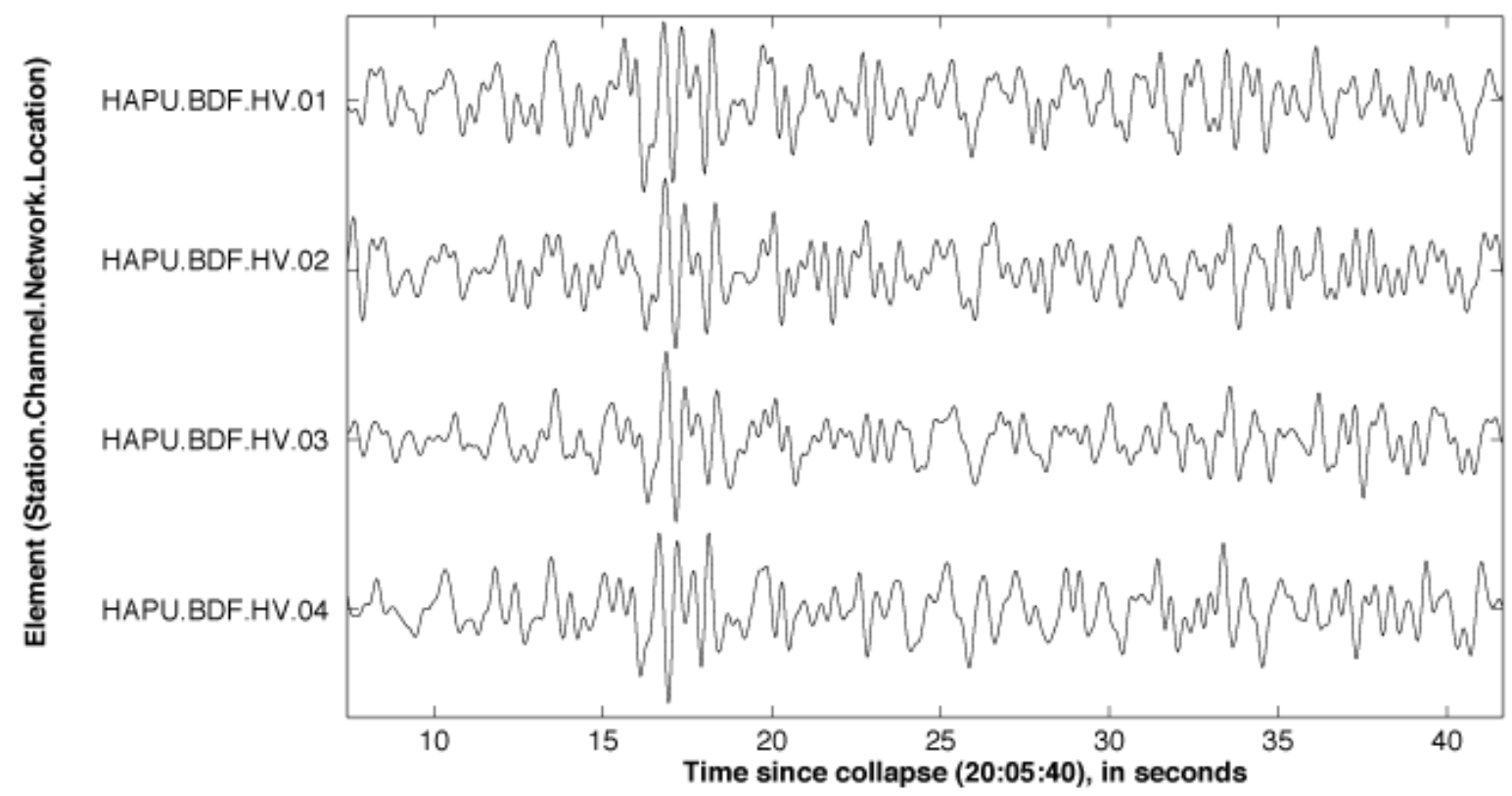

Figure 17. Graph showing infrasound records at each of the components in the HAPU array. The signal from the Pu'u 'Ō'ō pit collapse arrives at 20:05:57 UTC. Signals are filtered above the microbarom $(0.4 \mathrm{~Hz})$. 

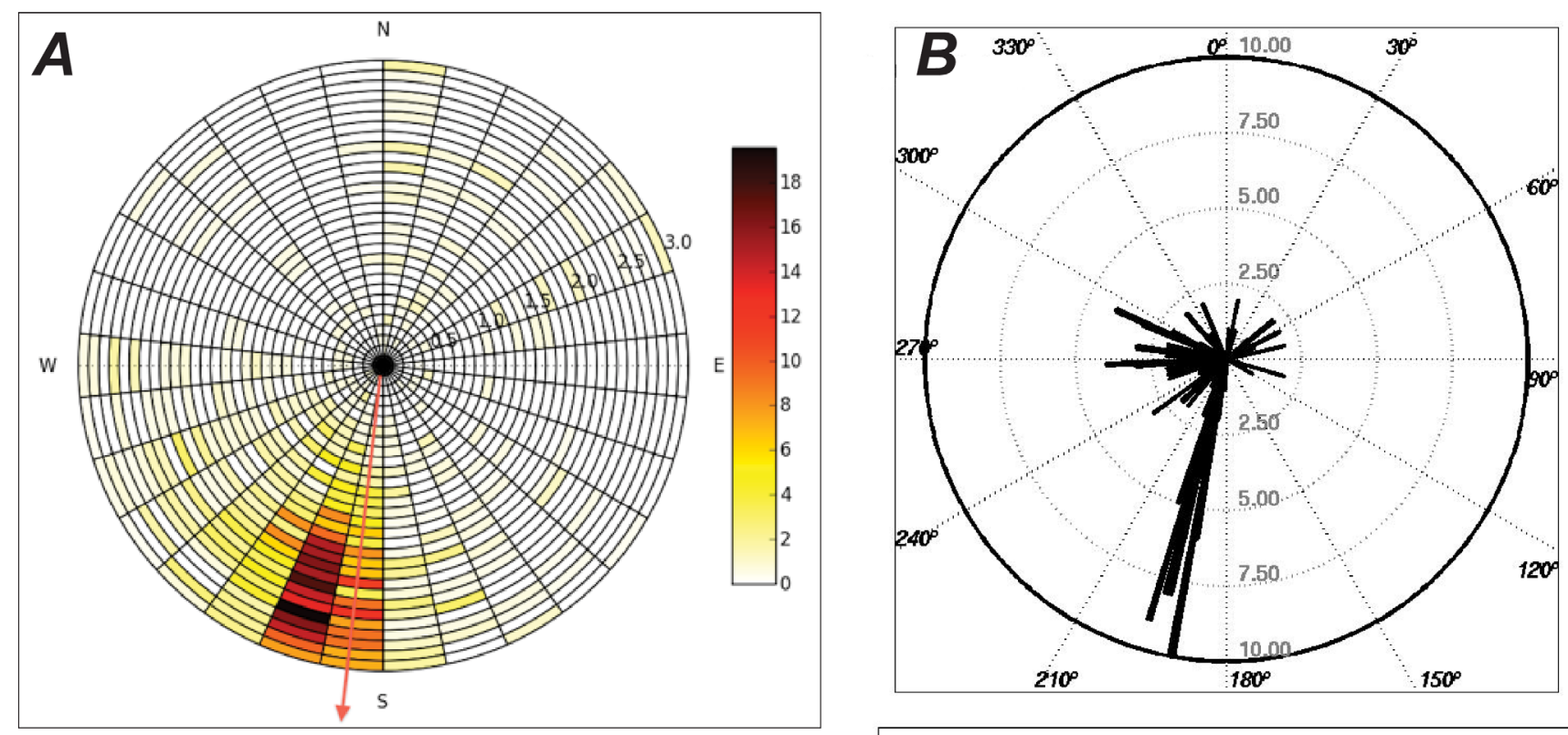

JD243 2012-08-30 : 20:05:18 => 20:07:18

Figure 18. Plots showing $\mathrm{f}-\mathrm{k}$ and $\mathrm{PMCC}$ analysis of the Pu'u 'Ō'ō pit collapse at the HAPU array. $A$, Polar plot of $f-k$ analysis for the pit collapse at Pu'u ' $\bar{O}$ ' $\overline{0}$. $B$, Histogram rose diagram from PMCC analysis for the pit collapse at Pu'u 'Ō'o. The expected back azimuth at the HAPU array is $187^{\circ}$ (red arrow in $A$ ). HAPU has a clear back azimuth towards the collapse in both analyses. Results of the event recorded at the AIND array ( $37 \mathrm{~km}$ from the pit collapse) did not show any signal in the proper direction. The AHUD array was not yet installed. 


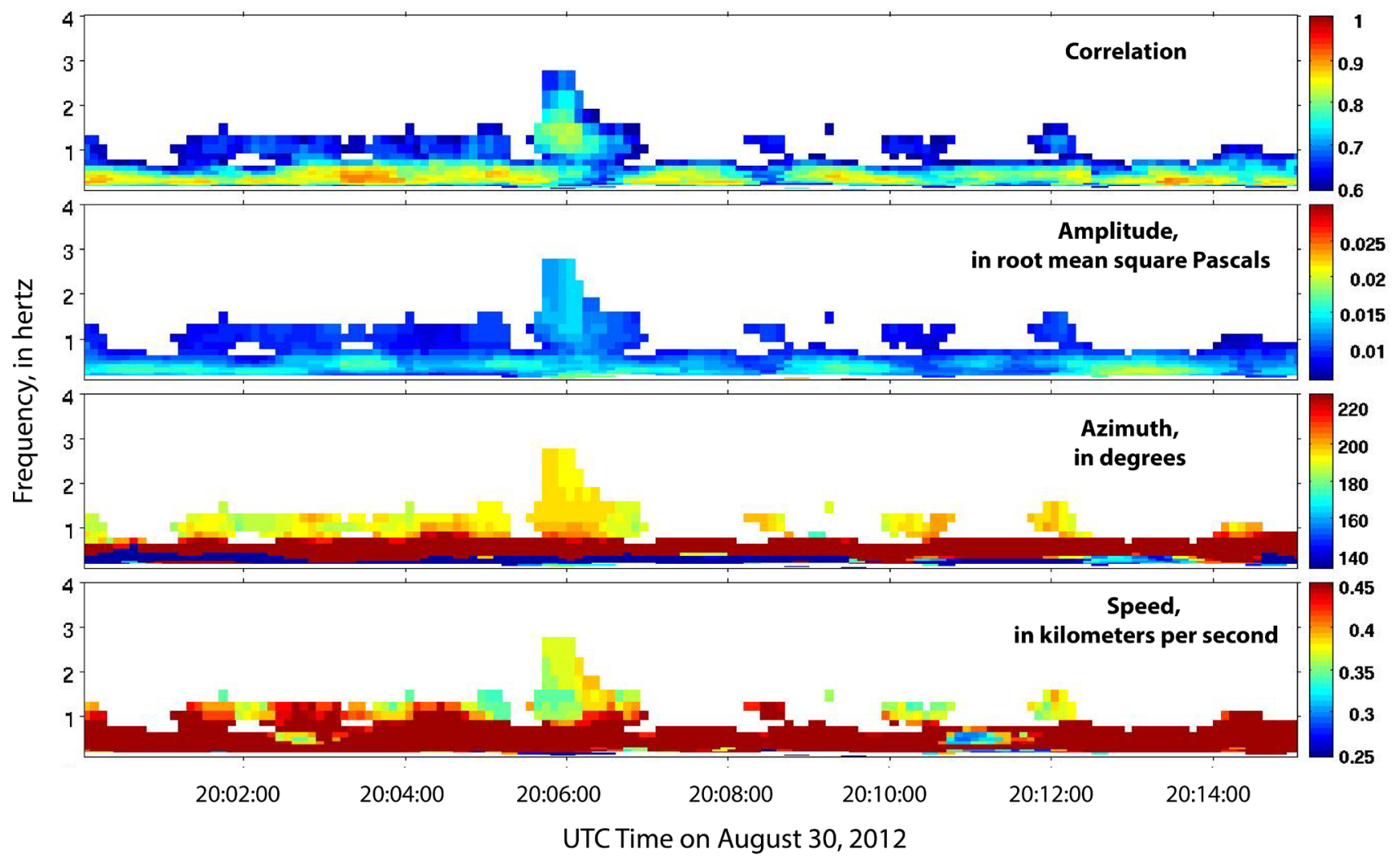

Figure 19. Graphs showing PMCC analysis of the Pu'u 'Ō'ō pit collapse at the HAPU array. The signal of interest occurs around 20:06:00 UTC. The correlation refers to the consistency of the waveform between array elements. Only detections with correlations above 0.6 are shown. The amplitude is the averaged amplitude across the array. Azimuth refers to the direction that the wave is originating from, and speed refers to the speed of the event across the array. The filtered waveforms are shown in figure 17.

\section{Rise-Fall Cycle at Halema'uma'u Crater: October 19, 2012, 8:00-16:00 UTC}

Rise-fall cycles at Kinlauea summit are caused by the trapping and releasing of gas within the lava lake (Patrick and others, 2011). Typically, gas release is concentrated into one or two spattering sources, which produce ample seismic and infrasonic tremor. At times, the spattering stops abruptly, and the level of the lava lake rises as the gas pushes the surface of the lava lake upward. Eventually, gas pierces the surface of the lava lake, and spattering resumes. In this section, we analyze two rise-fall cycles (fig. 20).

We have chosen to analyze a time period when the lava lake transitioned from rise (low infrasonic and seismic tremor) to fall (high infrasonic and seismic tremor) and back to rise. The fall begins October 19, 2012, at approximately 8:50 UTC and lasts until approximately 9:30 UTC and is accompanied by high seismic and infrasonic tremor (figs. 20,21). The next fall cycle extends between 12:00 and 13:20 UTC. A rise cycle continues from 13:20 UTC through the end of our analysis period. The AHUD infrasound clearly shows the fall part of the rise-fall cycle as a significant increase in highcorrelation detections calculated from WinPMCC. The increase in high-correlation detections was concurrent with spattering in the lava lake (fig. 22). Infrasonic signals on the AHUD array during 
periods of infrasonic tremor did not exceed $0.20 \mathrm{~Pa}$ (fig. 21). Detections of the rise fall cycle are not clear on AIND and HAPU.

Comparing the direction of quality detections between rise and fall cycles clearly shows the correlation of high tremor levels to both spattering at the summit and high-correlation infrasound detections from the direction of Halema'uma'u (fig. 23). During the fall cycles, the azimuth points unequivocally toward Halema 'uma' $u$, while during rise cycles, fewer detections are present with no obvious directionality toward Halema'uma'u.

The infrasonic tremor detected by WinPMCC apparently is too small to be obviously detected using the f-k method. We detected no reliable difference between rose diagrams from the f-k method during rise-fall cycles. This exemplifies the increased sensitivity that the PMCC algorithm has over the $\mathrm{f}-\mathrm{k}$ analysis method, most likely because of how the PMCC algorithm searches for detections across several narrow frequency bands.

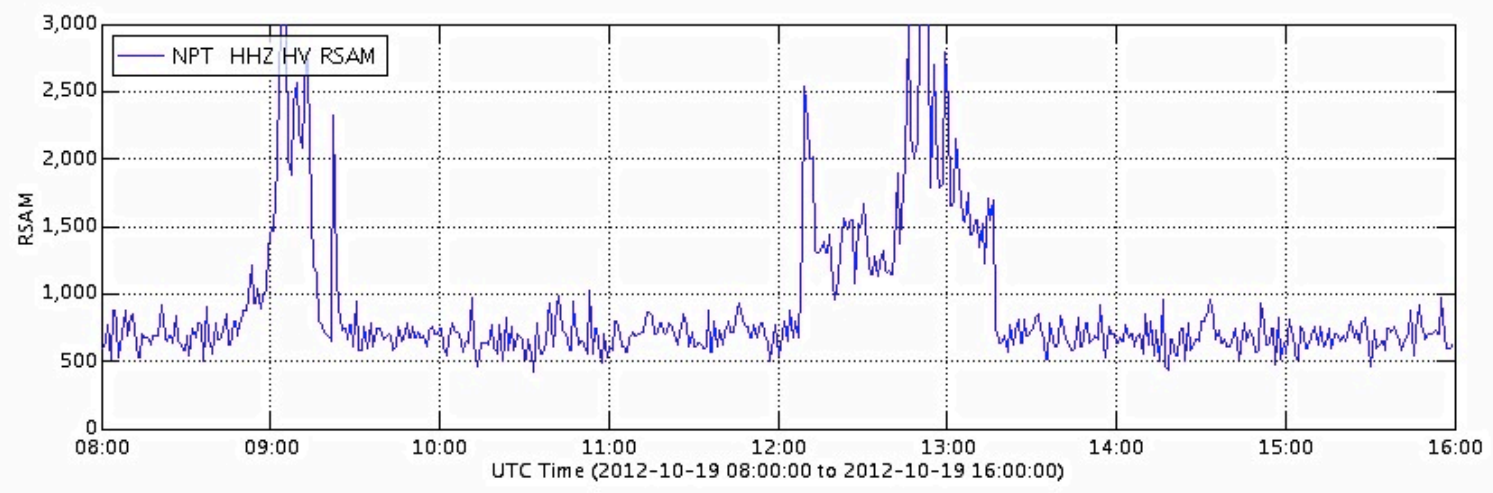

Figure 20. Graph showing 1-minute Realtime Seismic Amplitude Measurement (RSAM; Endo and Murray, 1991) at seismic station NPT ( $<1 \mathrm{~km}$ from Halema'uma'u vent) over 8 hours from 8:00-16:00 UTC on October 19, 2012. 


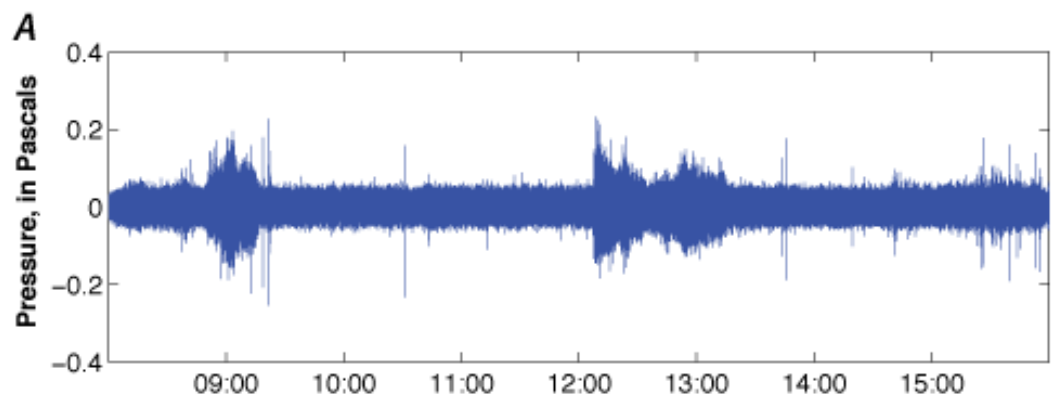

B

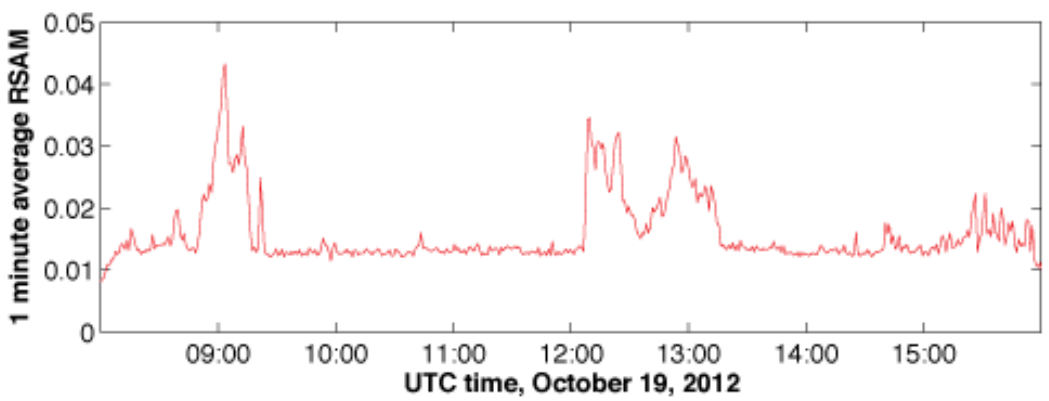

Figure 21. Graphs showing the infrasound signal during the Halema'uma'u rise-fall cycle at AHUD array, element 04. A, Bandpass-filtered infrasound signal $(0.4-3 \mathrm{~Hz})$ from element 04 of AHUD. B, 1-minute Realtime Seismic Amplitude Measurement (RSAM) of the bandpassfiltered infrasound signal. 


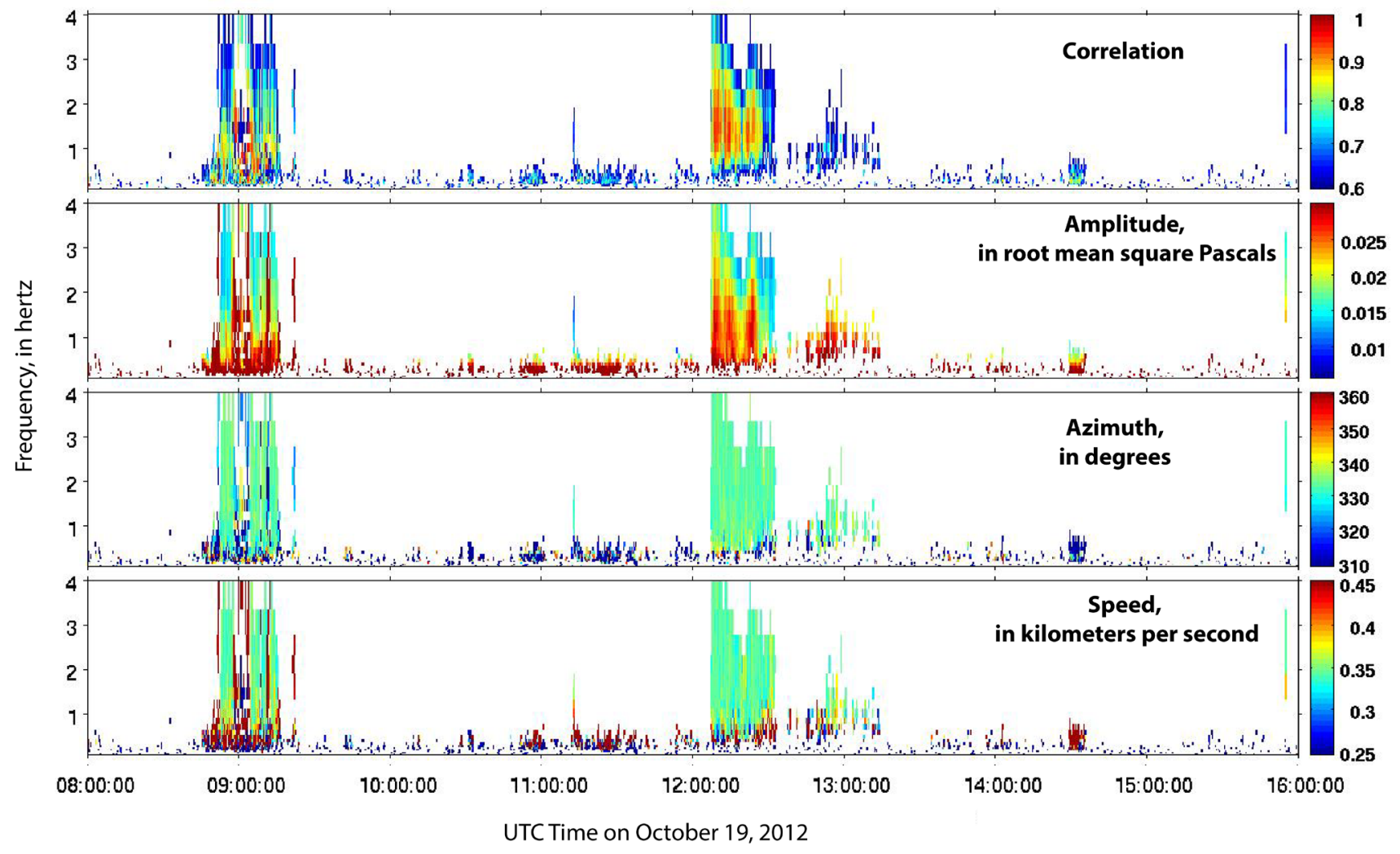

Figure 22. Graphs showing PMCC analysis of the Halema'uma'u rise-fall cycles at the AHUD array. The fall cycles are between approximately 8:50 and 9:30 UTC and between approximately 12:00 and 13:20 UTC. The correlation refers to the consistency of the waveform between array elements. Only detections with correlations above 0.6 are shown. The amplitude is the averaged amplitude across the array. Azimuth refers to the direction that the wave is originating from, and speed refers to the speed of the event across the array. 

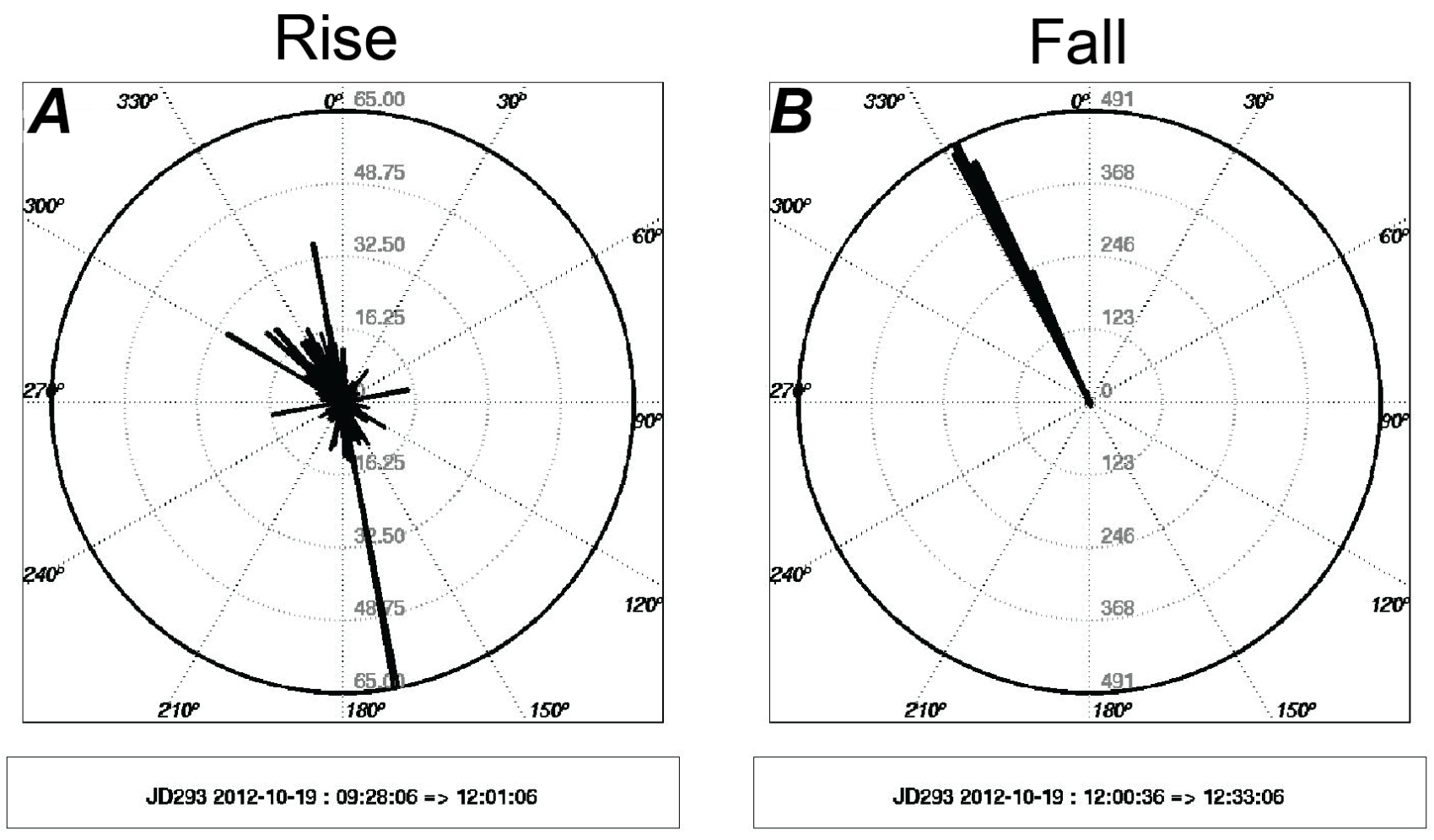

Figure 23. Rose plots showing PMCC analysis of the Halema'uma'u rise-fall cycle at the AHUD array. A, Rose plot of the rise segment, 9:28-12:01 UTC. $B$, Rose plot of the fall segment, 12:00-12:33 UTC. As expected, the fall portion has a clear signal toward Halema'uma' $u$, and the rise segment is scattered and does not have a clear back azimuth toward Halema'uma'u. Note the different number of coherent detections in each plot (gray numbers within circle).

\section{Conclusion}

The initial installation and location of the three infrasound arrays around Kîlauea Volcano has

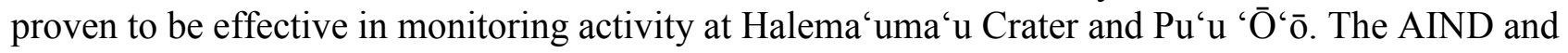
AHUD arrays are the main contributors for analyzing Kīlauea's summit lava lake activity, and, depending on the intensity of the event, these arrays can also detect occurrences at $\mathrm{Pu}^{\prime} \mathrm{u}{ }^{\prime}{ }^{\prime} \overline{\mathrm{O}}^{`} \overline{\mathrm{o}}$. The third station, HAPU, is most effective for activity at $\mathrm{Pu}^{\prime} \mathrm{u}{ }^{\prime}{ }^{\prime} \overline{\mathrm{O}}^{\prime} \bar{o}$ because of its close proximity to the source. It appears the arrays are sensitive to signals as weak as $0.05 \mathrm{~Pa}$. We have also shown the PMCC method to be more sensitive to our volcanic signals of interest than the f-k method, especially for analyzing infrasonic tremor. The f-k method appears adequate for the detection and characterization of discrete broadband signals. When infrasound is coupled with seismic, optical, and thermal data, it is possible to better characterize surface volcanic activity such as lava lake activity.

\section{Acknowledgments}

We wish to thank the HVO technician group for their support in installing the infrasound network. Dr. Yves Cansi provided us with the WinPMCC software. We would also like to thank ISLA for providing technical consultation and calibrations for our infrasound instruments. Darren Hart 
graciously tested our instruments to empirically determine the poles and zeros. Richard Lahusen and Matthew Haney provided comments that improved the final product. Lastly, Richard LaHusen and Kelly Swinford were critical in building the instruments and providing them to HVO. Jennifer Cooper extends her appreciation to HVO for hosting the volunteer program.

\section{References Cited}

Aki, K., and Richards, P.G., 2002, Quantitative seismology; theory and methods (2d ed.): Sausalito, Calif., University Science Books, 700 p.

Arent, S., and Fritts, D.C., 2000, Acoustic radiation by ocean surface waves: Journal of Fluid Mechanics, v. 415, p.1-21.

Arrowsmith, S.J., Whitaker, R.W., Taylor, S.R., Burlacu, R., Stump, B., Hedlin, M.A.H., Randall, G., Hayward, C., and ReVelle, D., 2008, Regional monitoring of infrasound events using multiple arrays; application to Utah and Washington State: Geophysical Journal International, v. 175, no. 1, p. 291300.

Badger, N.B., Garces, M., Perttu, A., Poland, M., and Thelen, W.A., 2012, Infrasonic jetting from the Kamoamoa fissure eruption, Kīlauea Hawai'i, 5-9 March 2011: Kona, Hawaii, AGU Chapman conference poster M-27, presented August 20, 2012.

Bedard, A.J., 1971, Seismic response of infrasonic microphones: Journal of Research of the National Bureau of Standards, v. 75C, no. 1, p. 41-45.

Beyreuther, M., Barsch, R., Krischer, L., Megies, T., Behr, Y. and Wassermann, J., 2010, ObsPy; a Python toolbox for seismology: Seismological Research Letters, v. 81, no. 3, p. 530-533, doi: 10.1785/gssrl.81.3.530.

Bowman, J.R., Baker, G.E., and Bahavar, M., 2005, Ambient infrasound noise: Geophysical Research Letters, v. 32, no. 9, L09803, 5 p.

Cansi, Y., 1995, An automatic seismic event processing for detection and location: Geophysical Research Letters, v. 22, no. 9, p. 1021-1024.

De Angelis, S., Fee, D., Haney, M., and Schneider, 2012, Detecting hidden volcanic explosions from Mt. Cleveland Volcano, Alaska, with infrasound and ground-coupled airwaves: Geophysical Research Letters, v. 39, no.21, L21312, 6 p.

Endo, E.T., and Murray, T., 1991, Real-time seismic amplitude measurement (RSAM)—a volcano monitoring and prediction tool: Bulletin of Volcanology, v. 53, no. 7, p. 533-545.

Fee, D., Garcés, M., Patrick, M., Chouet, B., Dawson, P., and Swanson, D., 2010, Infrasonic harmonic tremor and degassing bursts from Halema'uma'u Crater, Kilauea Volcano, Hawaii: Journal of Geophysical Research, v. 115, no. B11, B11316, 15 p.

Fee, D., and Matoza, R.S., 2013, An overview of volcano infrasound; from Hawaiian to Plinian, local to global: Journal of Volcanology and Geothermal Research, v. 249, p. 123-139.

Garcés, M., Hetzer, C., Merrifield, M., Willis, M., and Aucan, J., 2003, Observations of surf infrasound in Hawai'i: Geophysical Research Letters, v. 30, no. 24, 2264, 3 p.

Garces, M., and Le Pichon, A., 2011, Infrasound from earthquakes, tsunamis and volcanoes, in Meyers, R.A., ed., Extreme environmental events, complexity in forecasting and early warning: New York, Springer New York, p. 663-679.

Hedlin, M., Garces, M., Bass, H., Hayward, C., Herrin, G., Olson, J., and Wilson, C., 2002, Listening to the secret sounds on Earth's atmosphere: Eos (American Geophysical Union Transactions), v. 83, no. 48 , p. 557-565. 
Johnson, J.B., Aster, R.C., Ruiz, M.C., Malone, S.D., McChesney, P.J., Lees, J.M., and Kyle, P.R., 2003, Interpretation and utility of infrasonic records from erupting volcanoes: Journal of Volcanology and Geothermal Research, v.121, p. 15-63.

Le Pichon, A., and Cansi, Y., 2003, PMCC for infrasound data processing: InfraMatics, no. 2, p.1-9.

Le Pichon, A., Matoza, R., Brachet, N., and Cansi, Y., 2010, Recent Enhancements of the PMCC Infrasound Signal Detector: Inframatics, no. 26, p. 5-8.

Matoza, R.S, Fee D., and Garcés, M.A., 2010, Infrasonic tremor wavefield of the $\mathrm{Pu}^{\text {' } u}$ ' $\mathrm{O}^{`} \bar{o}$ crater complex and lava tube system, Hawaii, in April 2007: Journal of Geophysical Research, v. 115, no. B12, B12312, $16 \mathrm{p}$.

Matoza, R.S., Hedlin, M.A.H., and Garcés, M.A., 2007, An infrasound array study of Mount St. Helens: Journal of Volcanology and Geothermal Research, vol. 160, no. 3-4, p. 249-262.

McKisic, J.M., 1997, Infrasound and the infrasonic monitoring of atmospheric nuclear explosions: Department of Energy document PL-TR-97-2123, 310 p.

McNamara, D.E., and Buland, R.P., 2004, Ambient noise levels in the continental United States: Bulletin of the Seismological Society of America, v. 94, no. 4, p. 1517-1527.

Moran, S.C., Matoza, R.S., Garcés, M.A., Hedlin, M.A.H., Bowers, D., Scott, W.E., Sherrod, D.R. and Vallance, J.W., 2008a, Seismic and acoustic recordings of an unusually large rockfall at Mount St. Helens, Washington: Geophysical Research Letters, v. 35, no. 19, L19302, 6 p.

Moran, S.C., McChesney, P.J., and Lockhart, A.B., 2008b, Seismicity and infrasound associated with explosions at Mount St. Helens, 2004-2005, chap. 6 of Sherrod, E.R., Scott, W.E., and Stauffer, P.H., eds., A volcano rekindled; the renewed eruption of Mount St. Helens, 2004-2006: USGS Professional Paper 1750, p. 111-127.

National Academy of Sciences, 2002, Technical Issues Related to the Comprehensive Nuclear Test Ban Treaty: Washington, D.C., National Academy Press, International standard book number 0-30908506-3, $96 \mathrm{p}$.

Patrick, M., Wilson, D., Fee, D., Orr, T., and Swanson, D., 2011, Shallow degassing events as a trigger for very-long-period seismicity at Kîlauea Volcano, Hawai'i: Bulletin of Volcanology, v. 73, no. 9, p. 1179-1186.

Preparatory Commission for the Comprehensive Nuclear-Test-Ban Treaty Organization, 2011, Annual Report 2011: Vienna, Austria, Provisional Technical Secretariat of the Preparatory Commission for the Comprehensive Nuclear-Test-Ban Treaty Organization, $73 \mathrm{p}$.

Rost, S., and Thomas, C., 2002, Array seismology: Methods and applications: Review of Geophysics, v. 40 , no. 3, p. 2-1-2-27. 